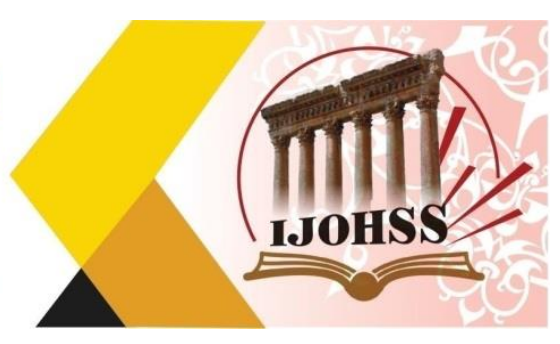

\title{
الإحالة وأثرها في تماسك القاعدة الصَّرفيَّة ووضوحها (شرح ابن عقيل أنموذجًا)
}

\author{
د. أبو حنيفة عمر الثريف علي عمر الثراب

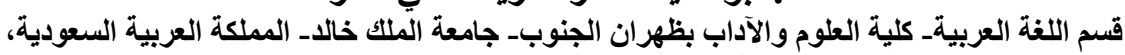

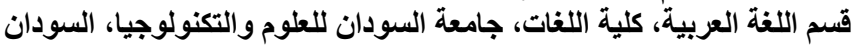

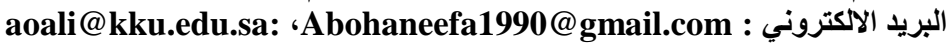 \\ د. محمد فوزي فتوح سليمان \\ قسم اللغة العربيةـ كلية العلوم والآداب بظهران الجنوبــ جامعة الملكل خالدـ المملكة العربية السعودية \\ البريد الالكتروني: mftooh@kku.edu.sa \\ د. رقية إبراهيم الحاج بلدري \\ جامعة الملك خالد، كلية العلوم والآداب بظهران الجناج الجنوب، قسم اللغة العربية \\ rhaj@kku.edu.sa البريد الاكترونية
}

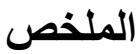

يتناول البحثُ الإحالةَّة في التأليف الصّرفي و أثر ها في تماسك النَّص ووضوح القاعدة الصرفيَّة في شرح ابن عقيل على ألفية ابن ماللك؛ وقد أتت أهمبة البحث في أنَّهَ يُلقي الضو هـ على مسألة مهمة، وهي توضيح معنى الإحالة في

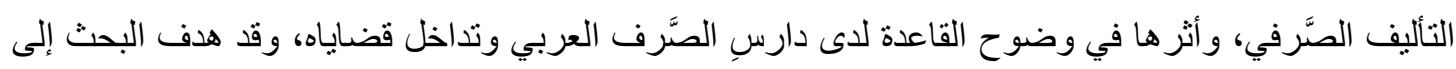
معرفة معنى الإحالة وبيان أدو اتها، وتوضيح العلاقة بين القاعدة المحيلة والمحال إليها في شرح ابن عقيل، وقد اتبحَ البحث المنهج الوصفي التحليلي لملاءمته طبيعة الدّرّاسة.

الكلمات المفتاحية: الإحالة، شرح ابن عقيل، تماسك النص، القاعدة الصَّرفيَّة. 


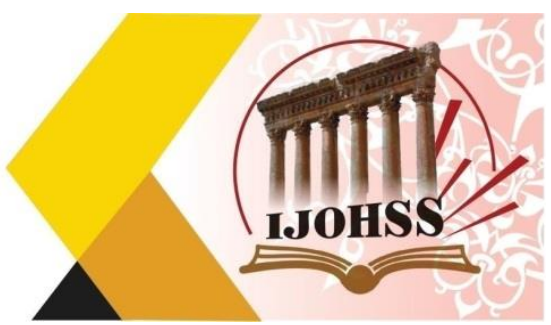

\title{
Reference and its Effect on the Consistency and Clarity of the Morphological Rule (Ibn Aqeel as a model)
}

\author{
Dr. Abohaneefa Omeralshareef Ali Omer \\ Department of Arabic, College of Art \& Sciences-Dhahran Alajnoub, King Khalid University, \\ KINGDOM OF SAUDI ARABIA . Email; aoali@kku.edu.sa Department of Arabic, College of \\ Languages- Sudan University of Science \& Technology. Sudan. \\ Email; Abohaneefa1990@gmail.com \\ Dr. Mohamed Fawzy Fotouh Soliman \\ Department of Arabic, College of Art \& Sciences-Dhahran Alajnoub, King Khalid University, \\ KINGDOM OF SAUDI ARABIA . Email mftooh@kku.edu.sa \\ Dr. Roqaya Ibrahim El-Haj Badry \\ Department of Arabic, College of Art \& Sciences-Dhahran Alajnoub, King Khalid University, \\ KINGDOM OF SAUDI ARABIA Email: rhaj@kku.edu.sa
}

\begin{abstract}
The study tackles reference in morphological composition and its effect on the text cohesion and the clarity of the morphological rule in dealing with some linguistic structures by Ibn Aqil in his explanation of Al Alfiya of Ibn Malik. The significance of this research arises from that it sheds light on a crucial issue, which is clarifying the meaning of the reference in morphological composition, and its effect on the clarity of the rule for the Arabic morphologist and the overlapping of its issues. The main objective of this research is to understand the meaning of refence and its tools, and to clarify the relationship between the referent and the referral rule as illustrated by Ibn Aqil. The research followed the descriptive analytical method for its relevance to the nature of the study.
\end{abstract}

Keywords: Reference, Ibn Aqeel Explanation, Cohesion, Morphological Rule. 


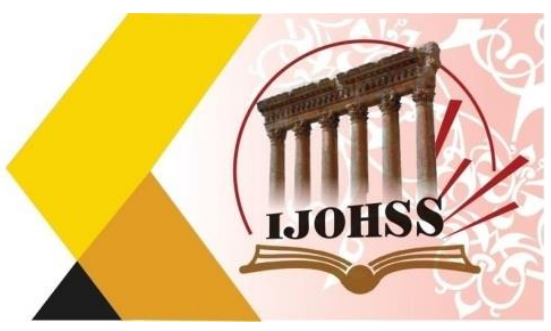

احتلَّ التأليف الصَّرفي مكانةً كبيرة لدى علماء اللغة بين العلوم اللغويَّة، حيثُ كان قسيمًا للنّحو في التأليف، ولَمَّا

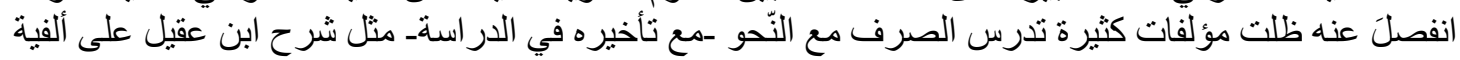

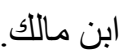

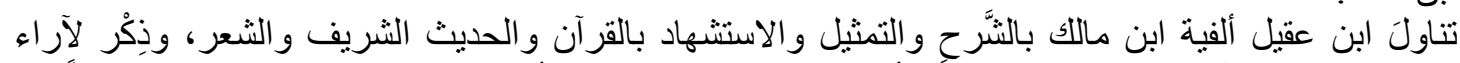

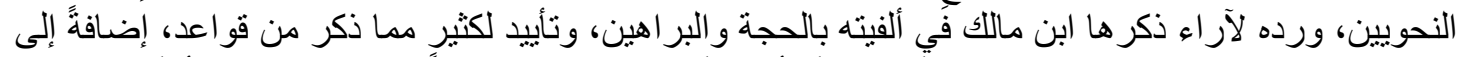

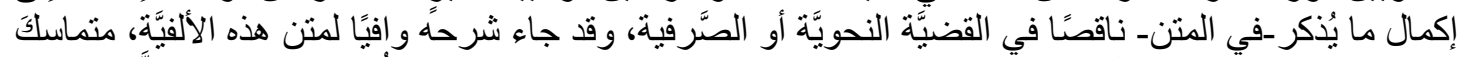

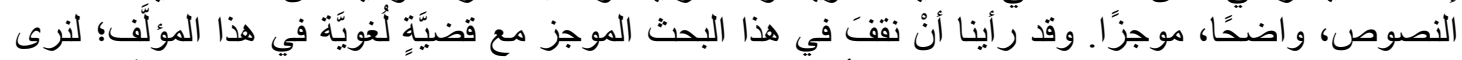

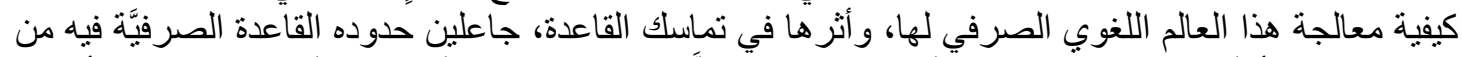

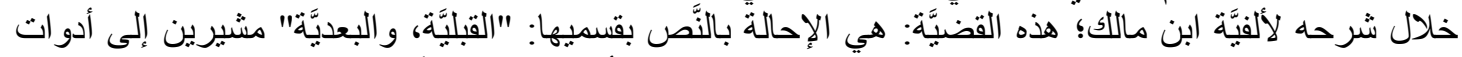

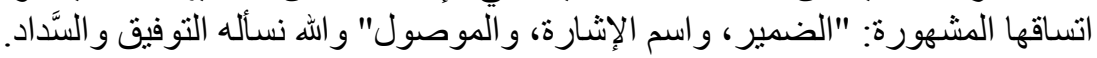

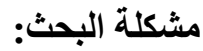

يُعالج البحثث بالدر اسة مفهوم الإحالة، وأنو اعها و أثر ها في تماسك القاعدة الصرفية لدى ابن عقيل من خلال شرحه الألفية ابن ماللك.

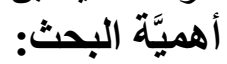

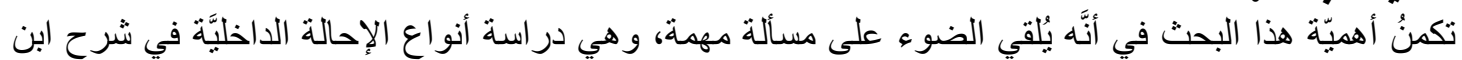

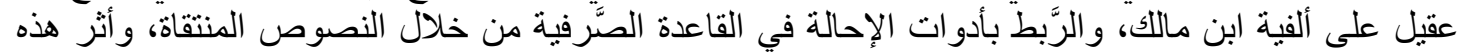

الأدوات في تحقيق تماسك هذه القاعدة.

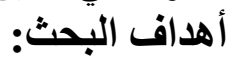
ئهدف البحث إلى:

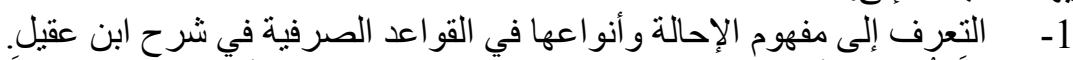

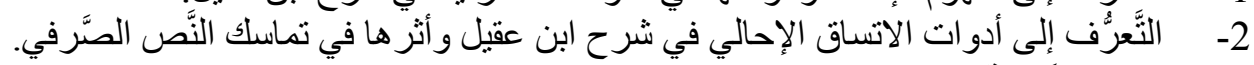

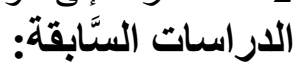

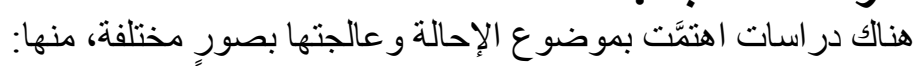

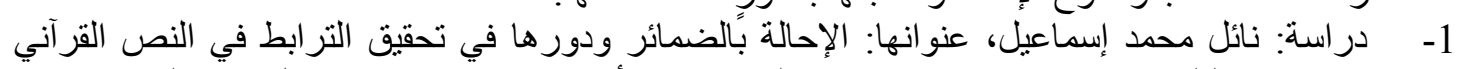

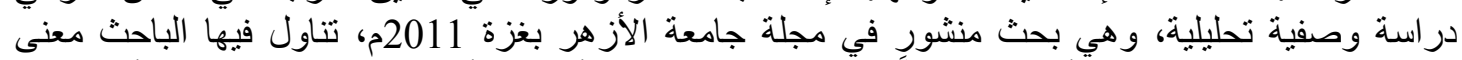

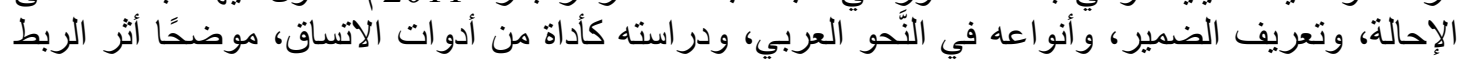
بالضمير في آي الذكر الحكيم.

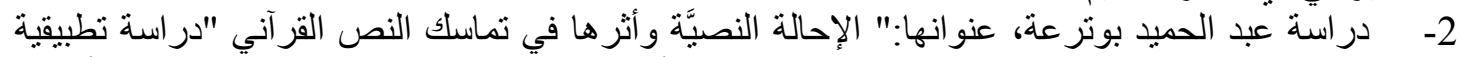

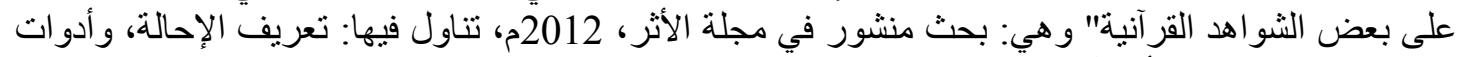

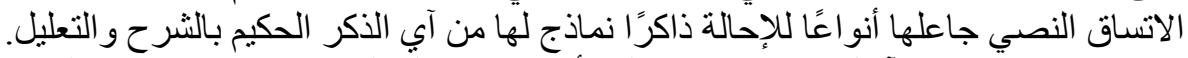

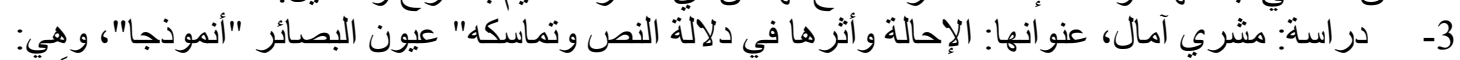

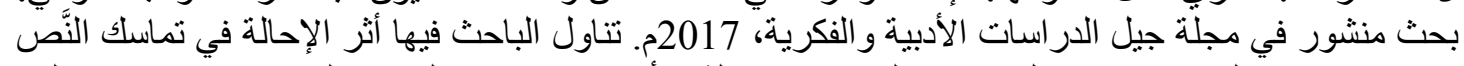

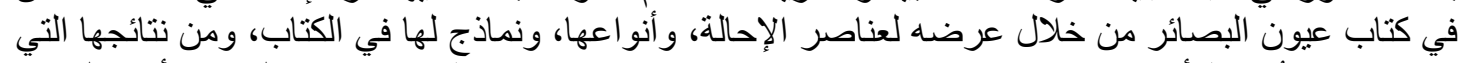

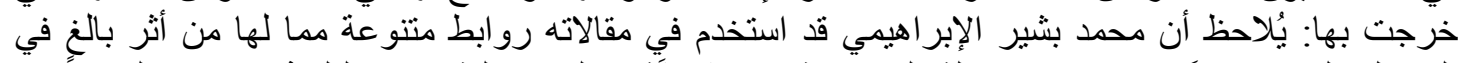

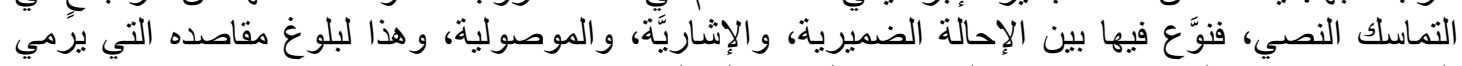

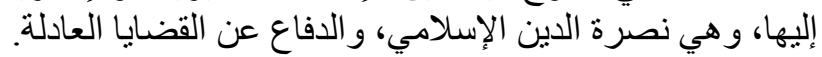
منهج البحث: المنهج الُْنَُّع في هذا البحث، هو المنهج الوصفي التحليلي لملاءمته طبيعة الدّر اسة. 


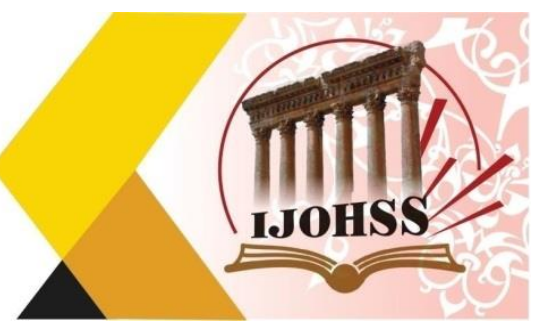

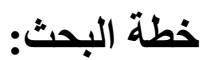

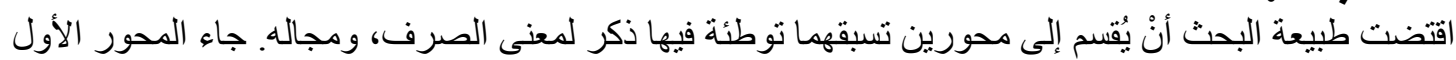

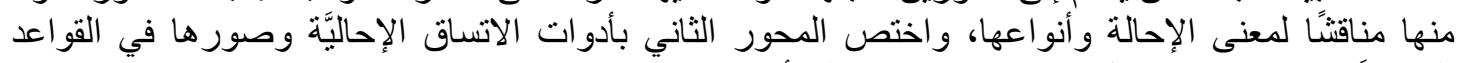

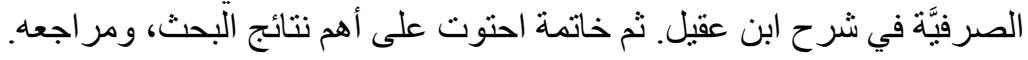

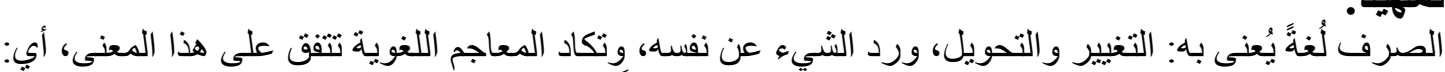

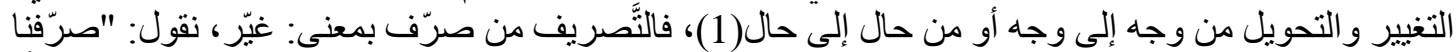

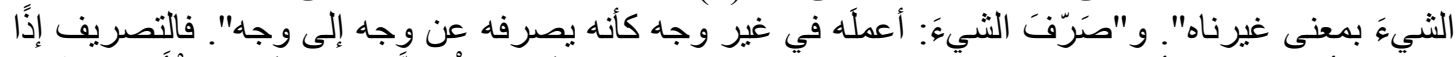

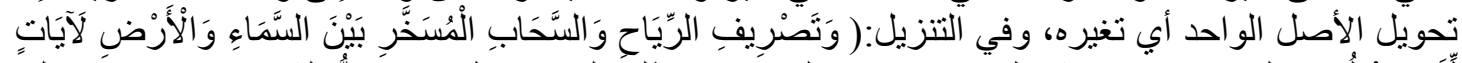

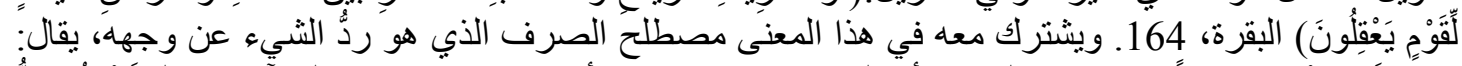

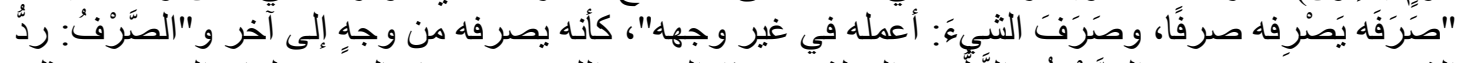

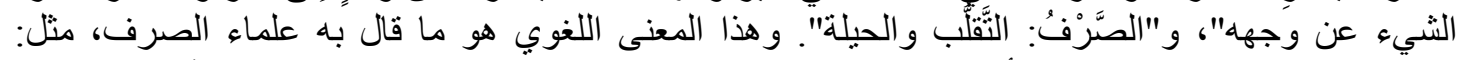

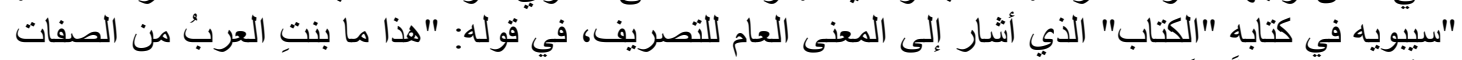

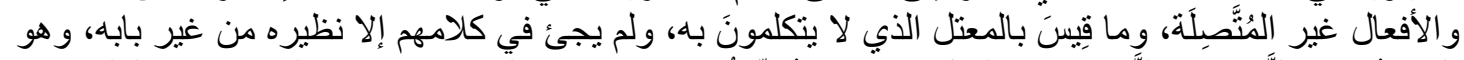

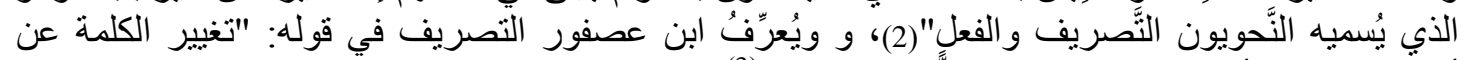

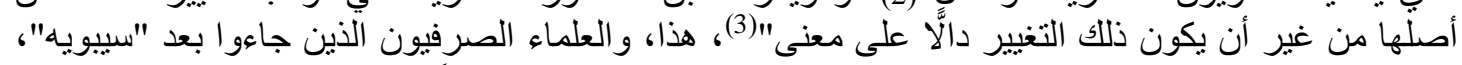

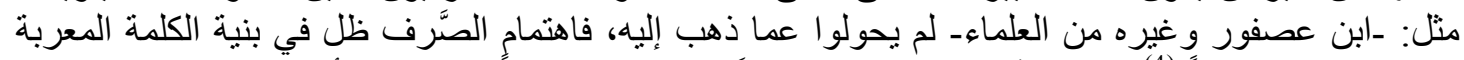

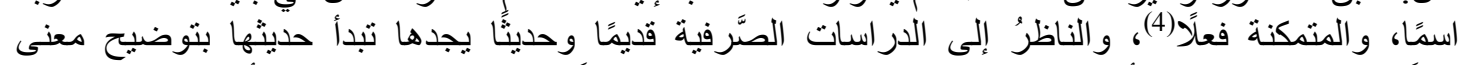

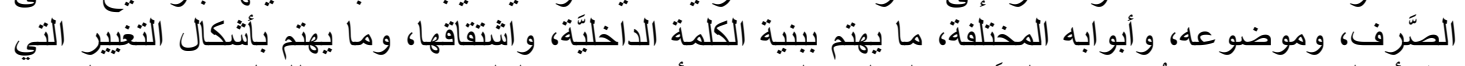

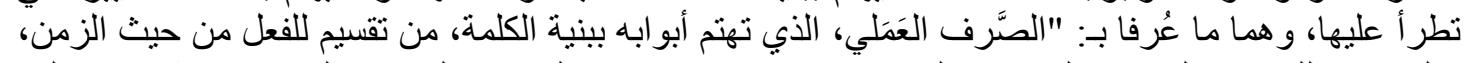

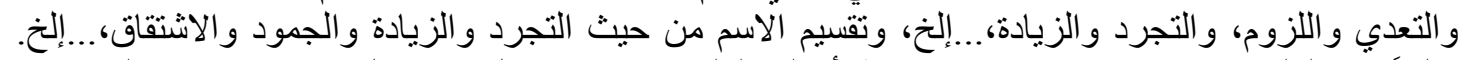

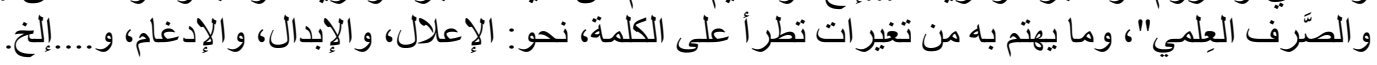

\section{المحور الأول- مفهوم الإحالة وأنواعها:

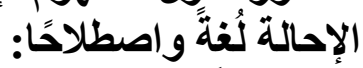

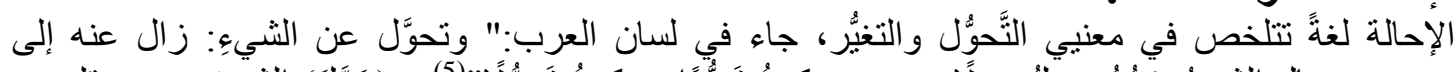

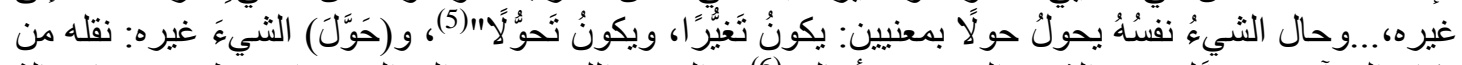

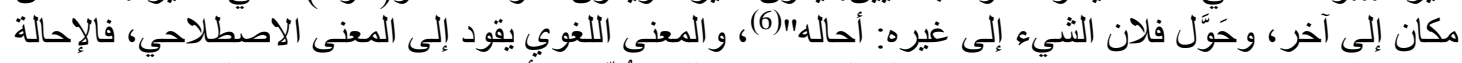

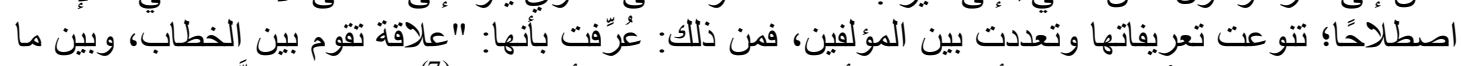

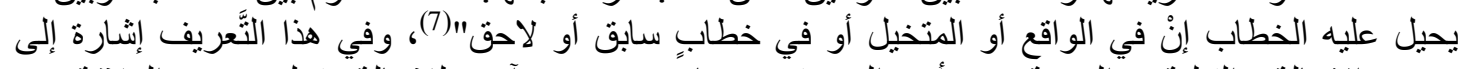

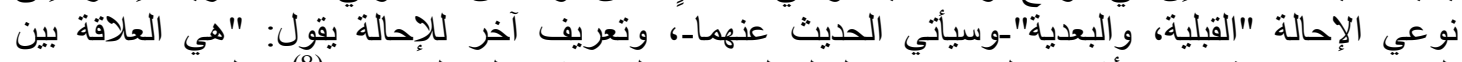

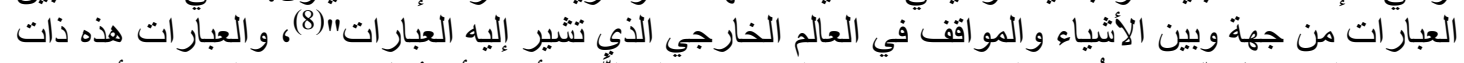

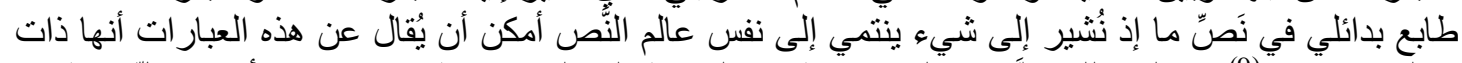

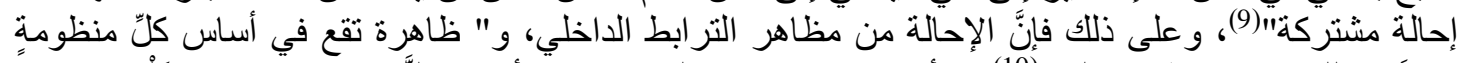

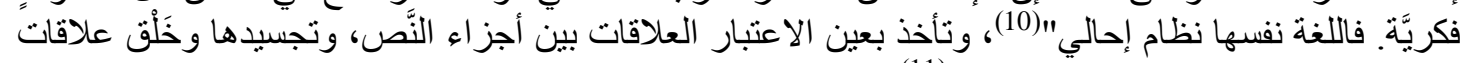

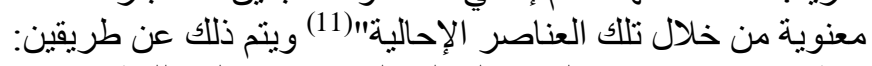

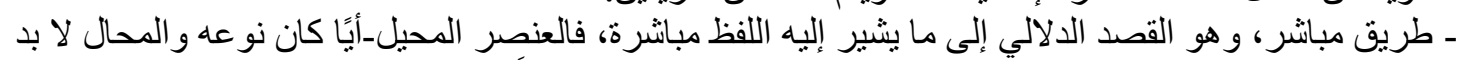

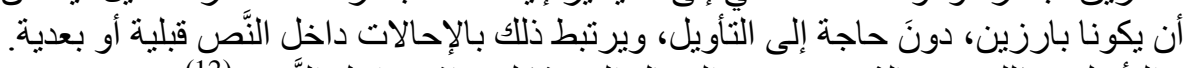

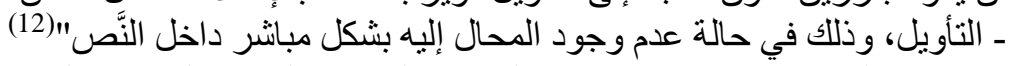

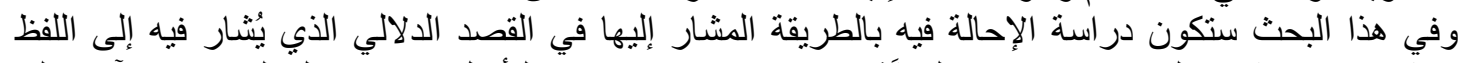

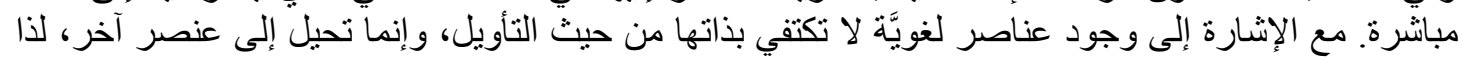




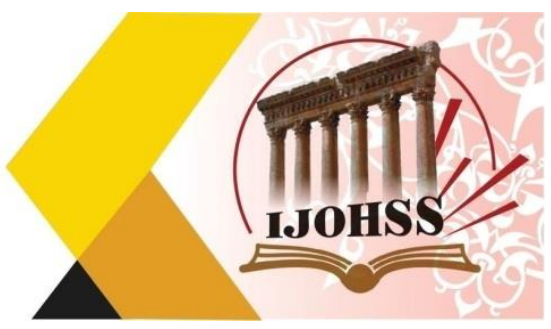

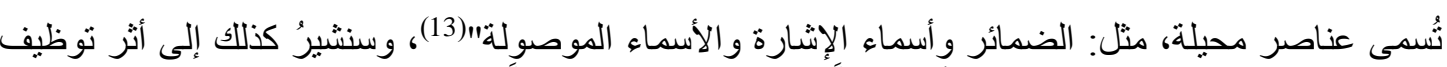

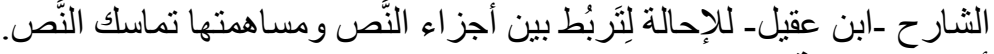

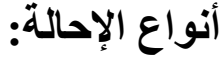

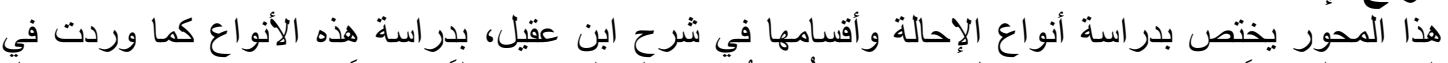

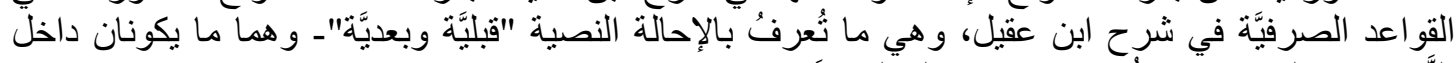

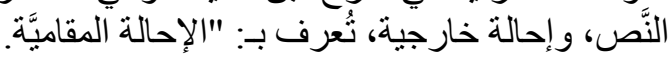

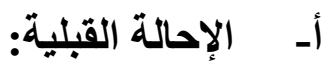

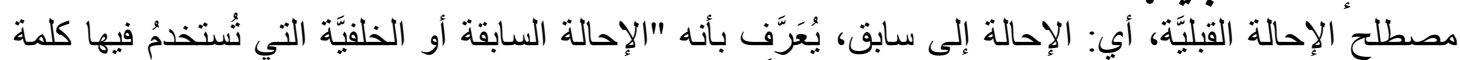

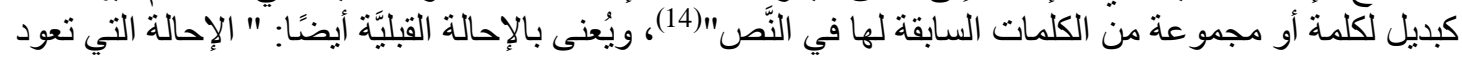

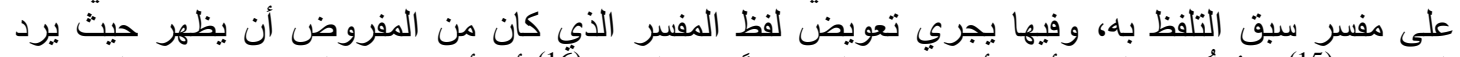

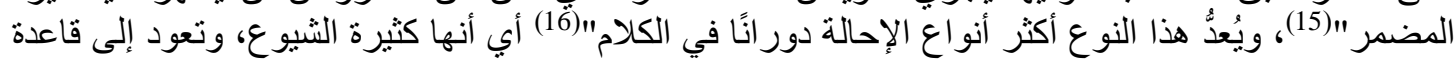

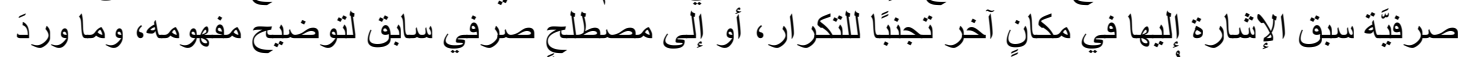

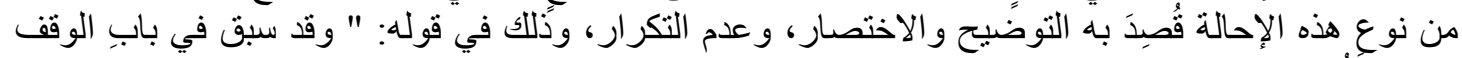

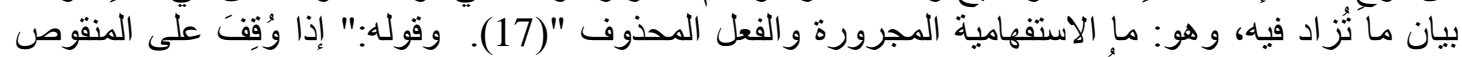

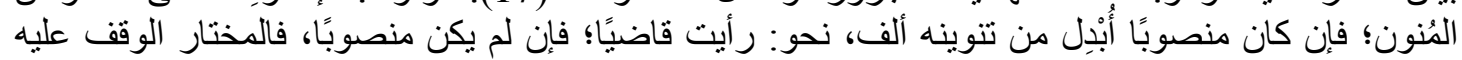

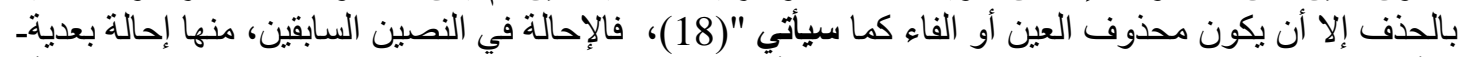

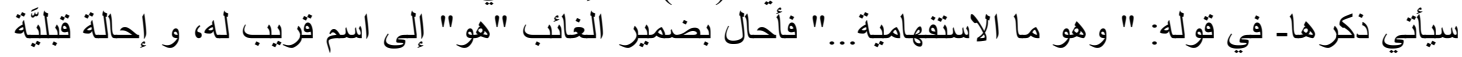

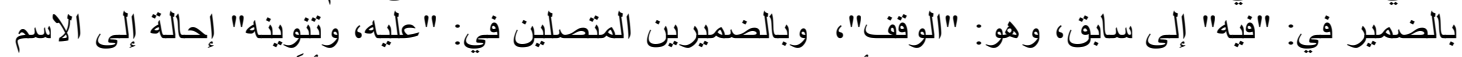

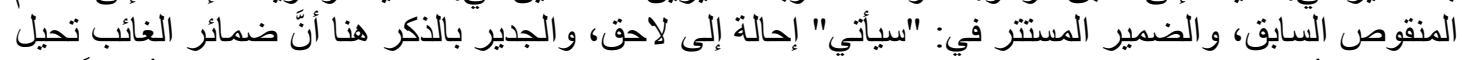

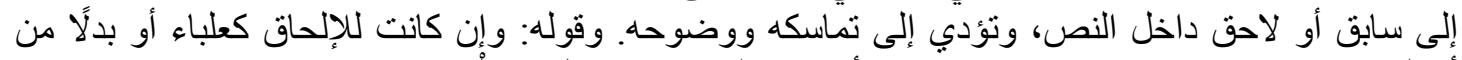

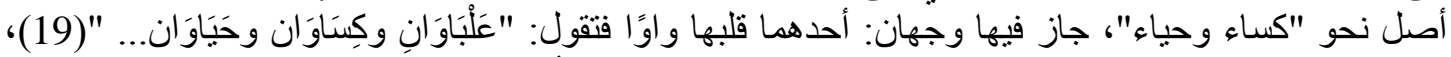

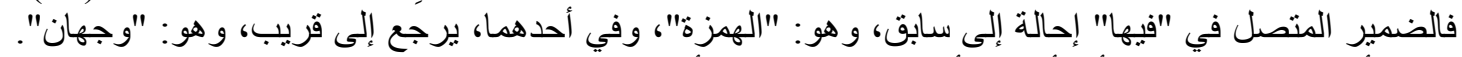

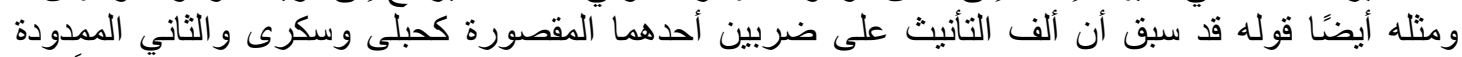

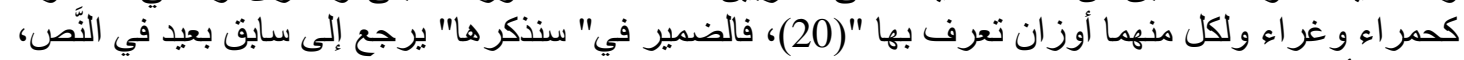

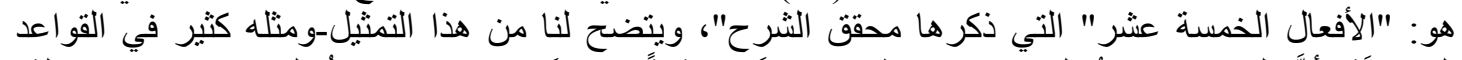

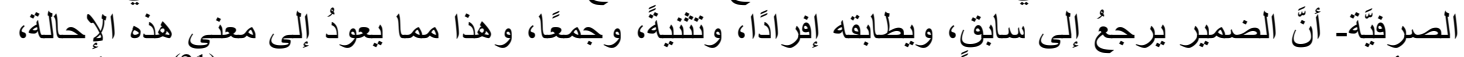

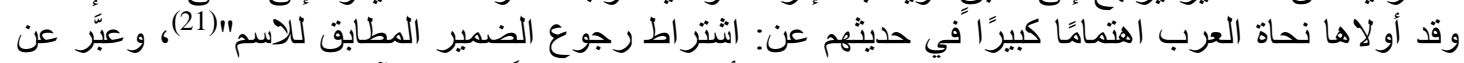

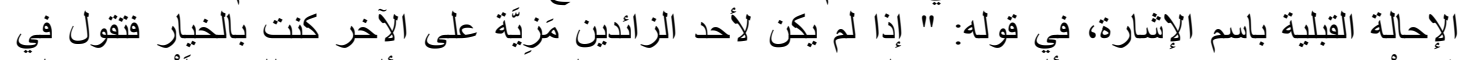

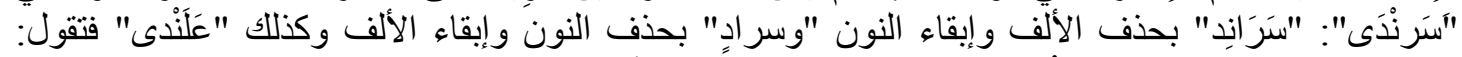

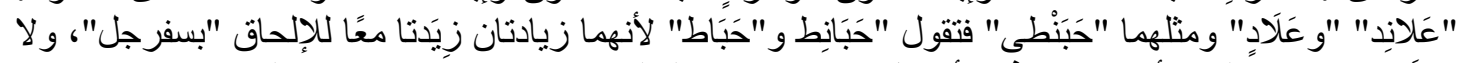

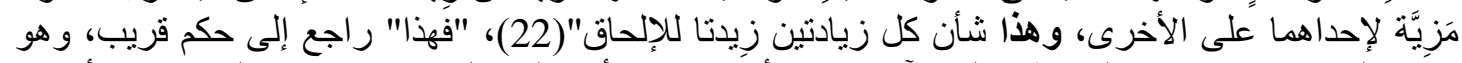

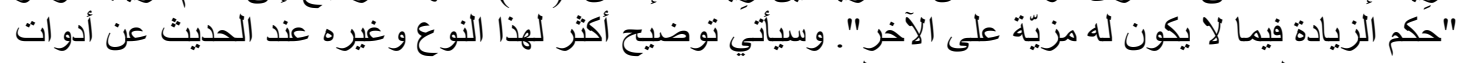

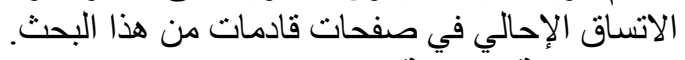

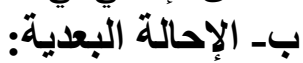

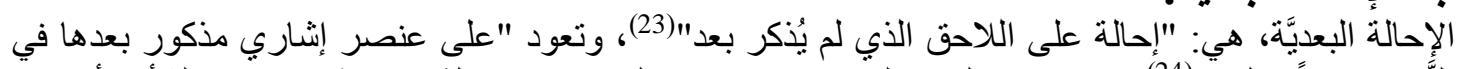

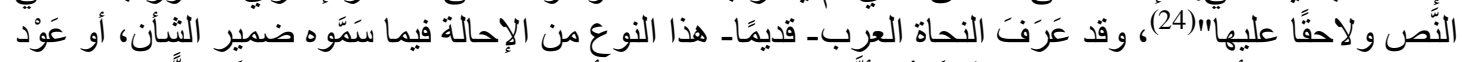

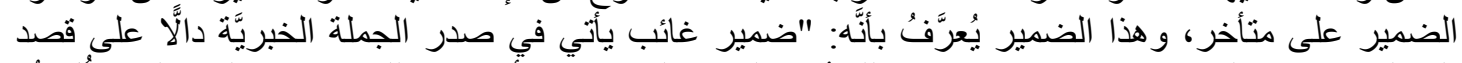

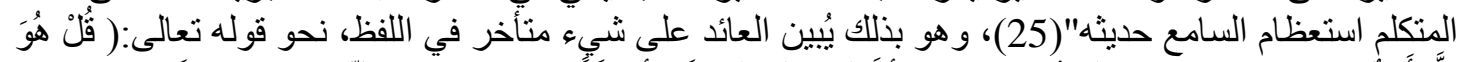

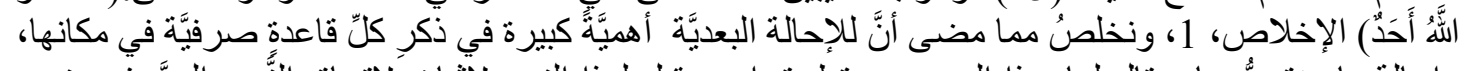

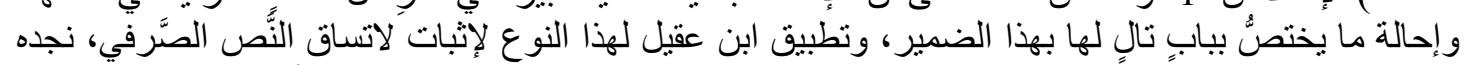

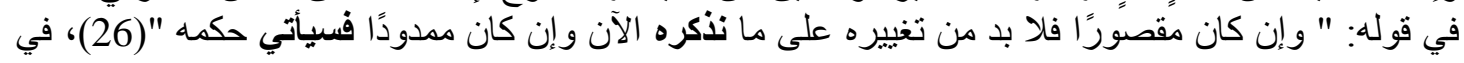




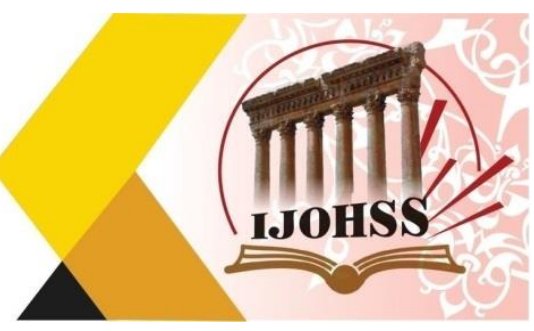

قوله "نذكره، وسيأتي" إحالة بعدية، وهي موجودة داخل النَّص. وكذلك "سيأتي" في موضع آخر آخر في قوله: "

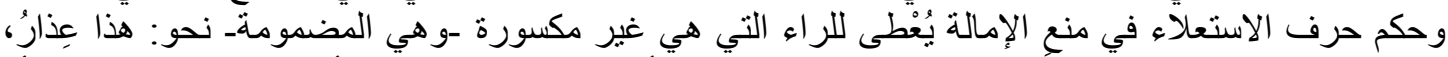

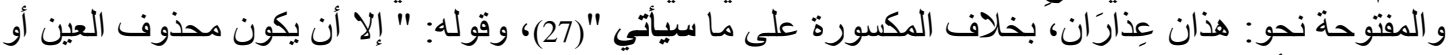

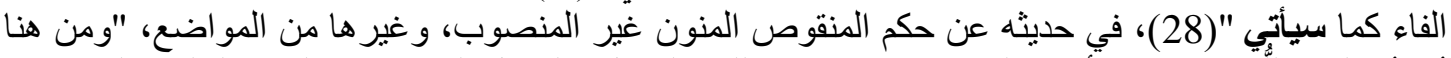

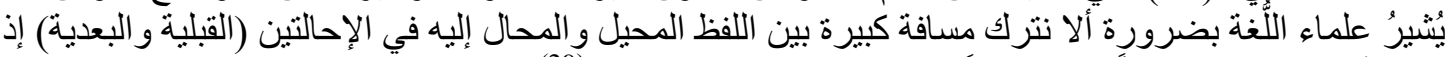

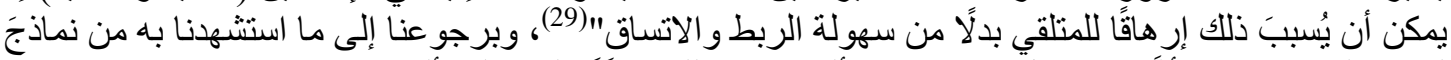

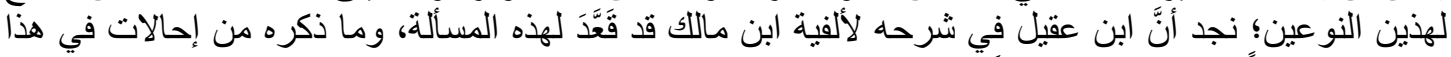

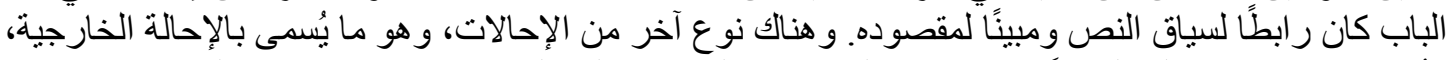

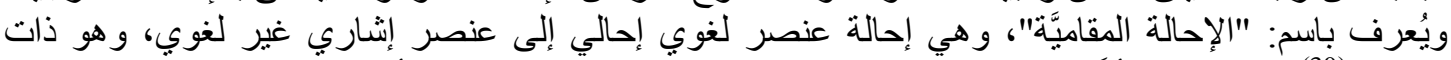

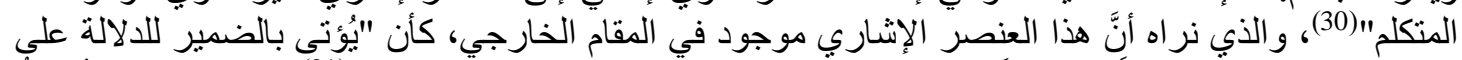

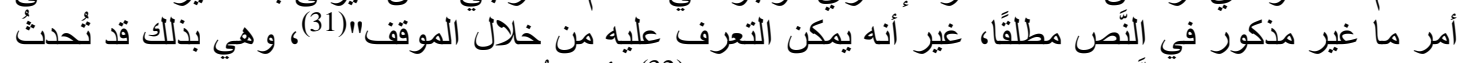

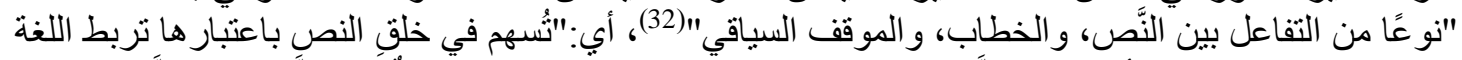

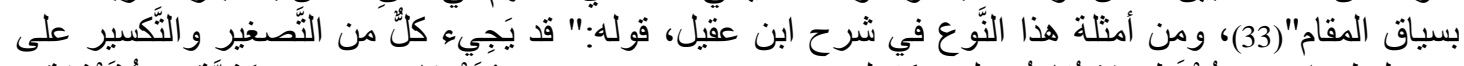

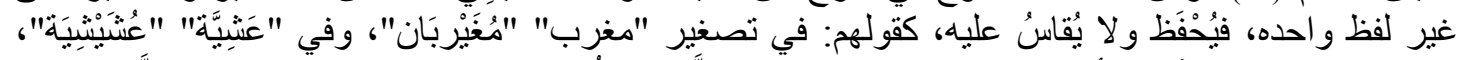

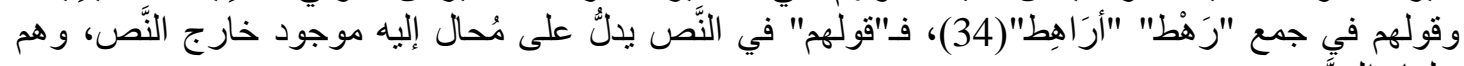

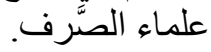

\section{المحور الثاني- أدوات الاتساق الإحاليَّة:}

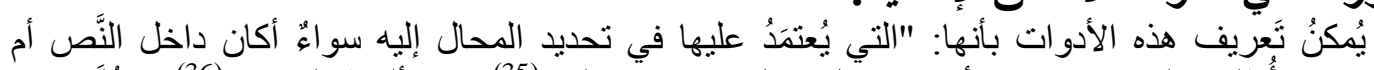

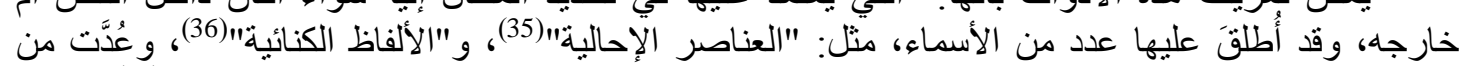

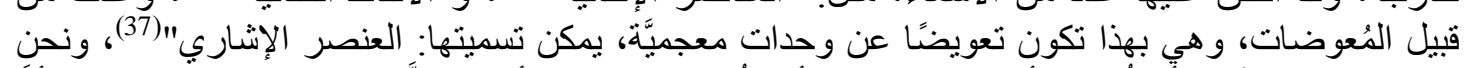

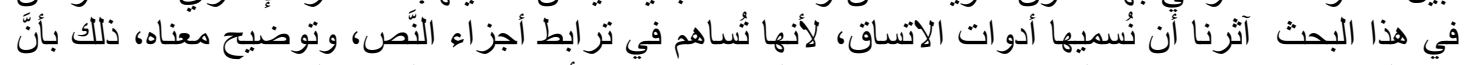

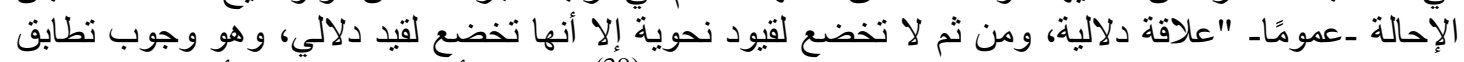

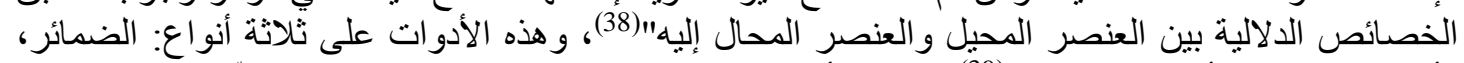

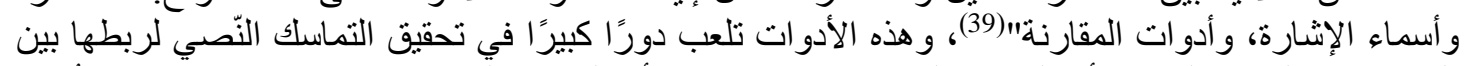

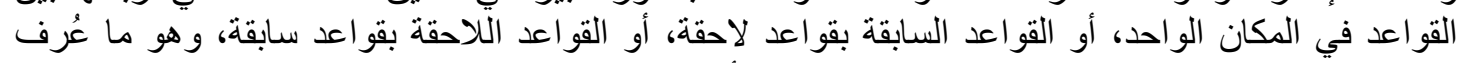

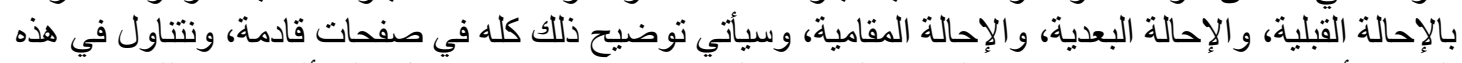

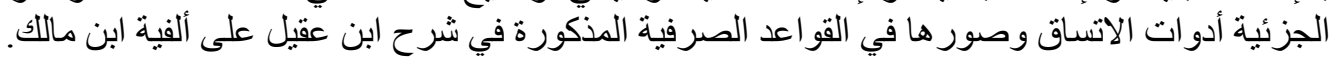

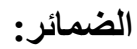

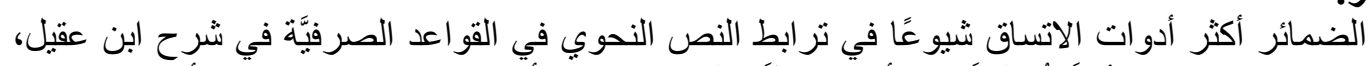

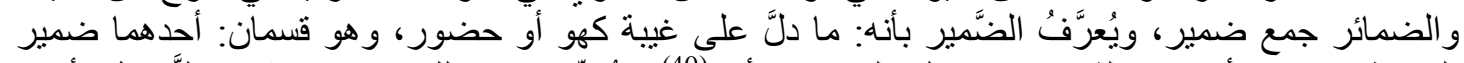

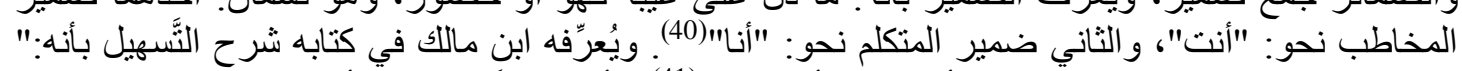

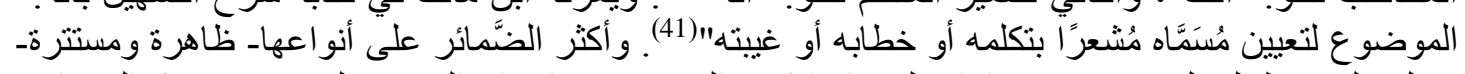

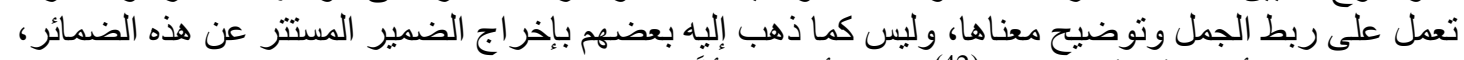

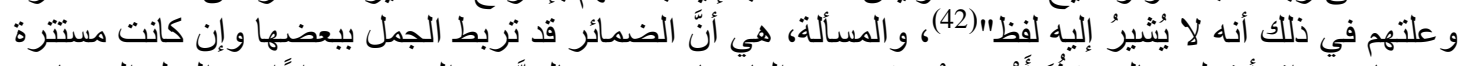

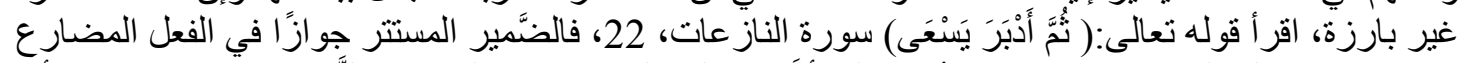

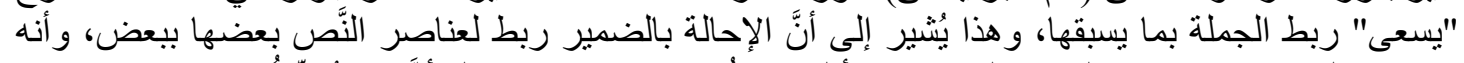

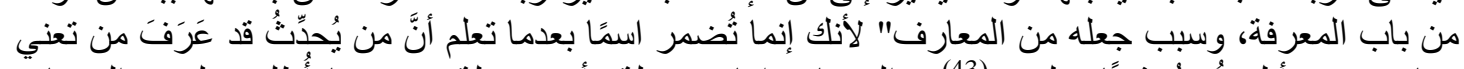

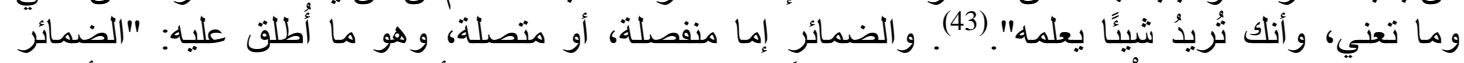

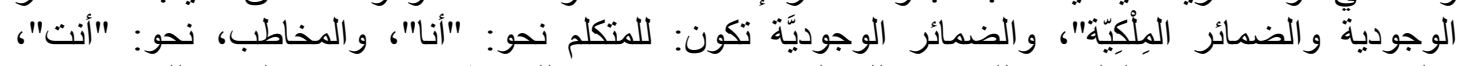

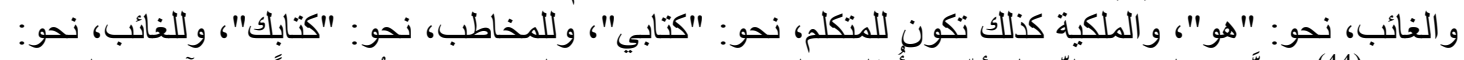

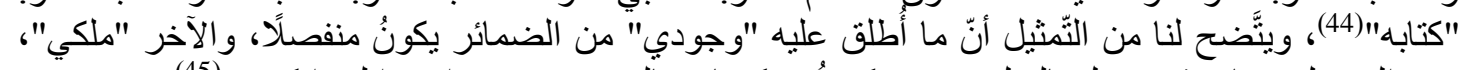

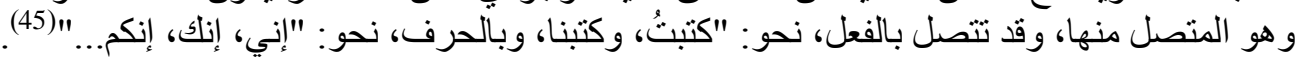




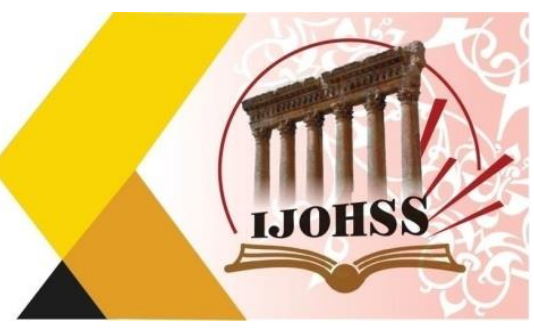

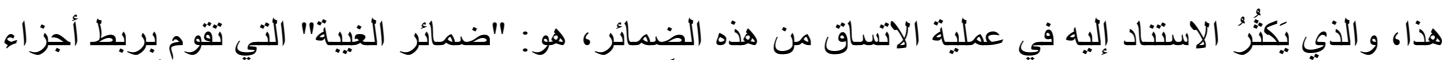

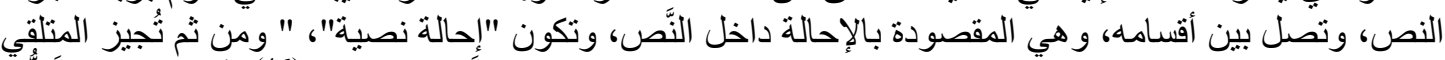

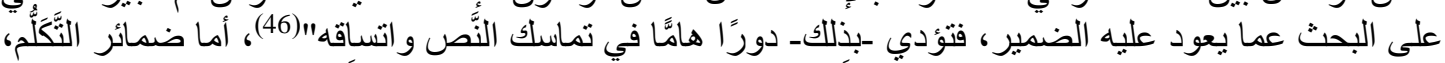

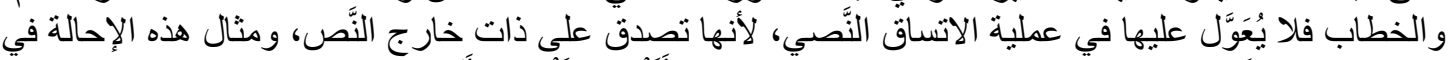

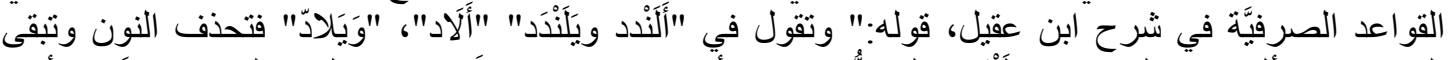

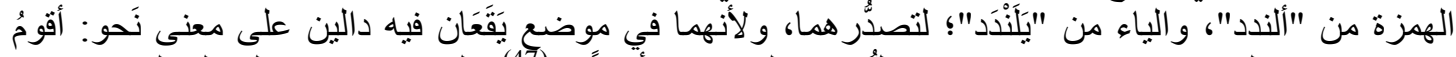

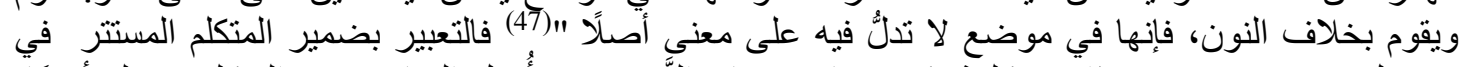

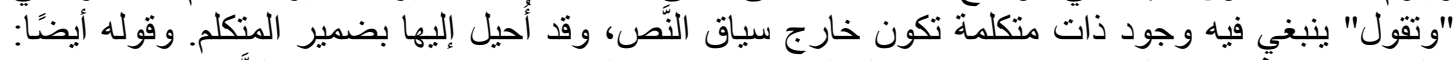

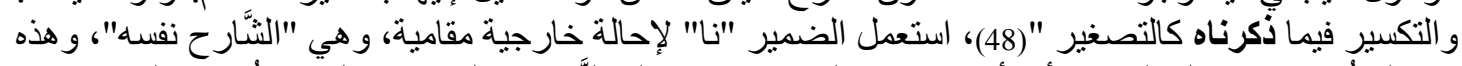

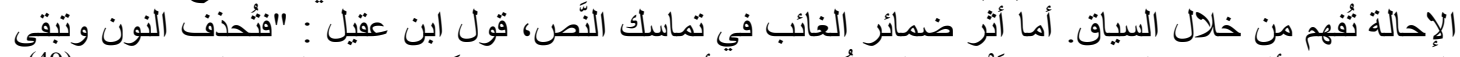

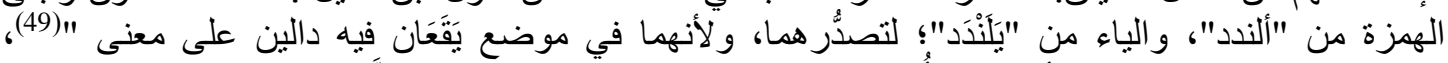

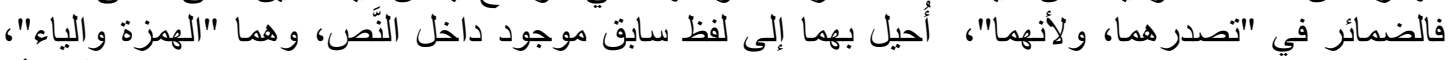

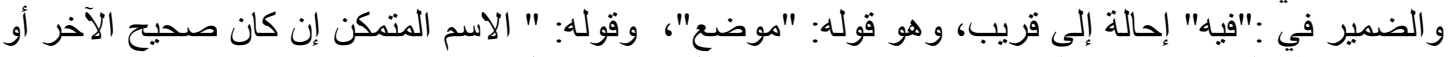

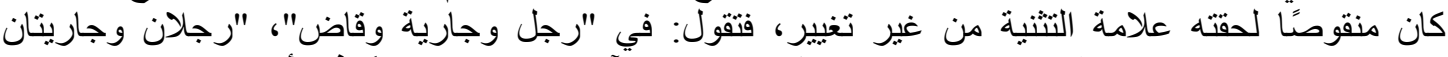

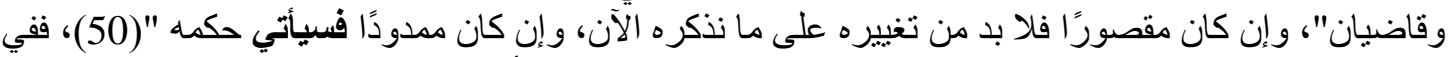

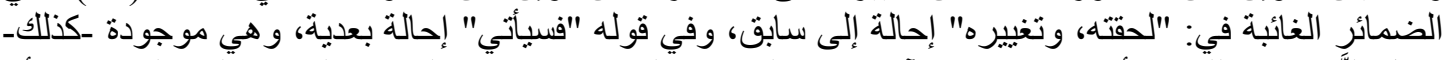

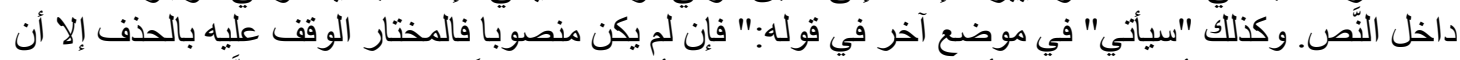

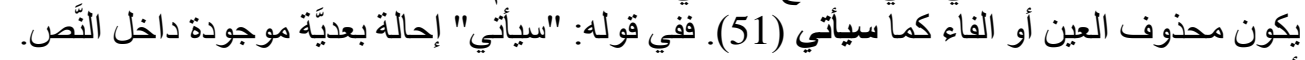

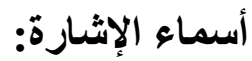

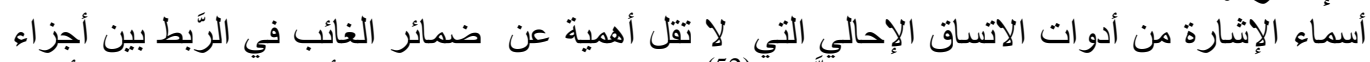

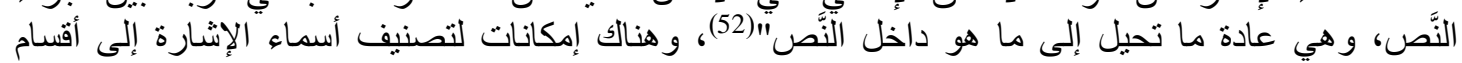

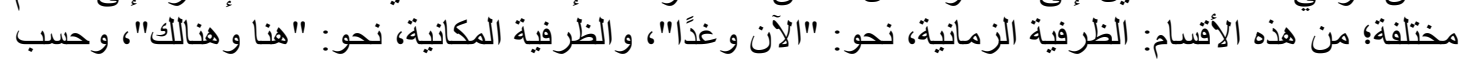

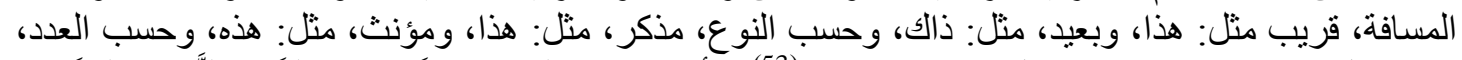

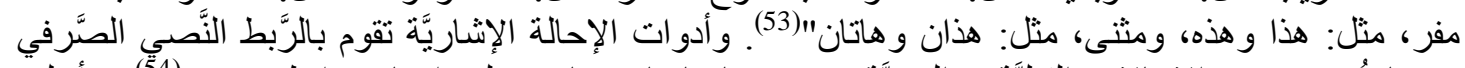

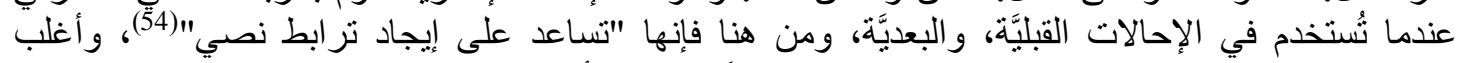

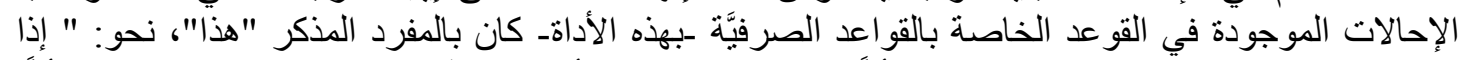

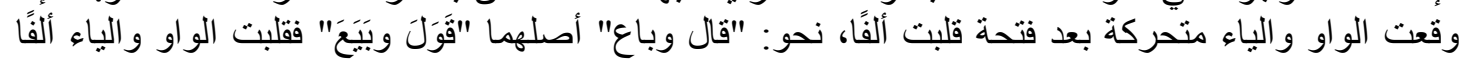

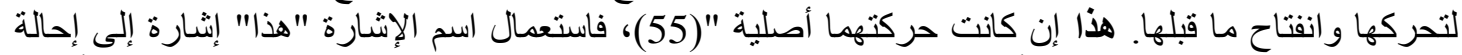

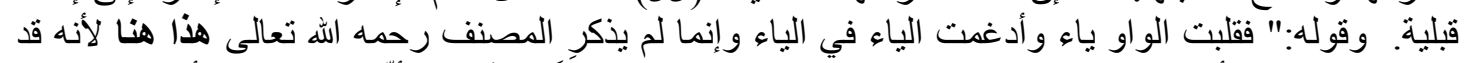

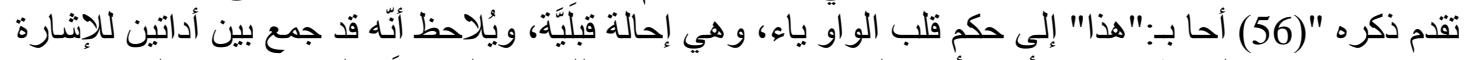

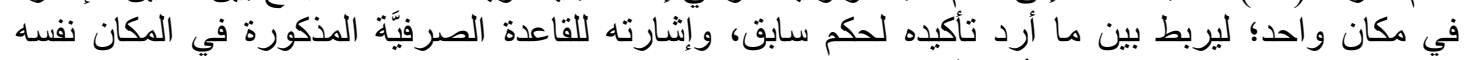

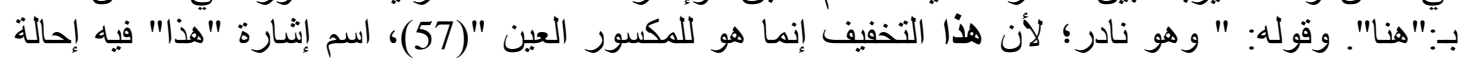

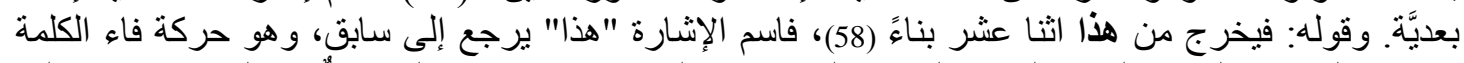

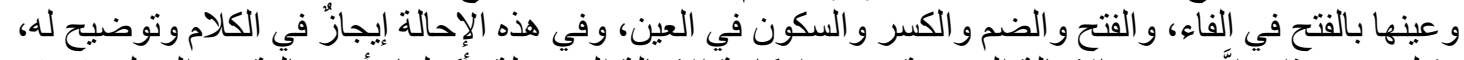

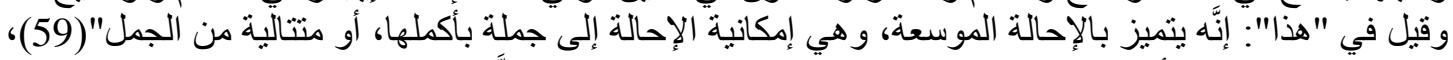

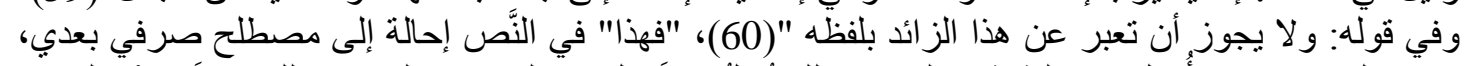

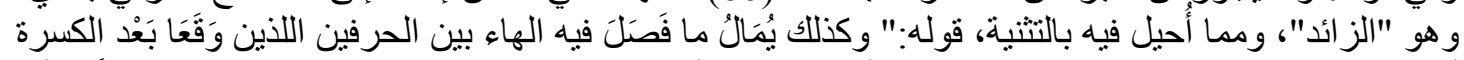

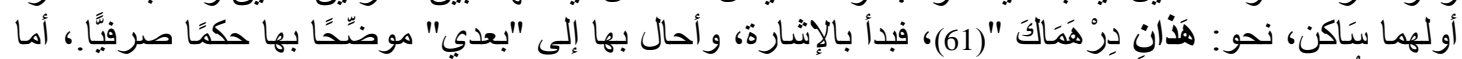

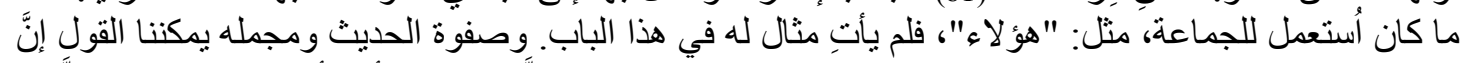

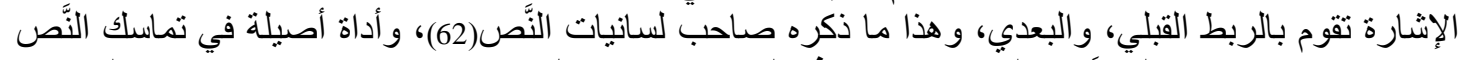

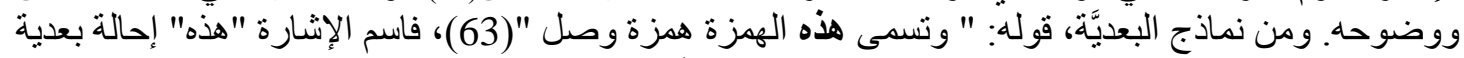

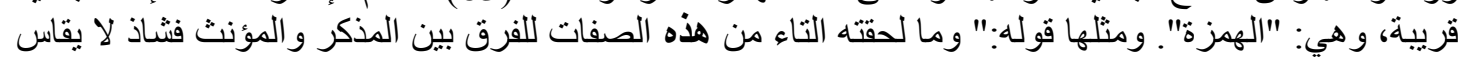




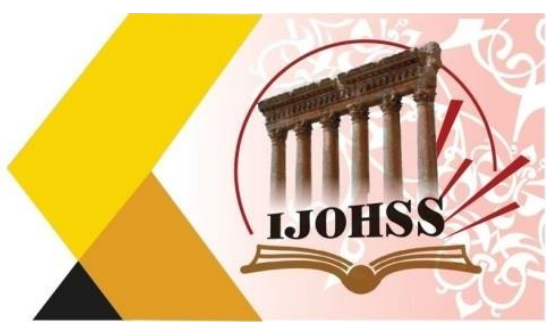

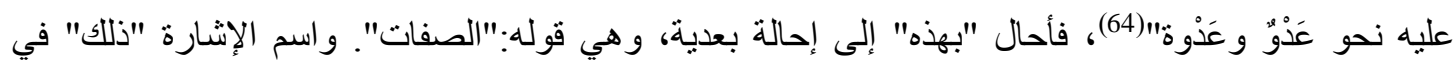

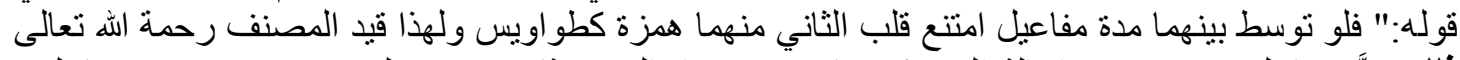

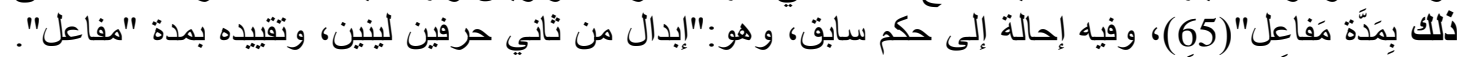
المذكورة سابقًا ولاحقًا.

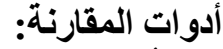

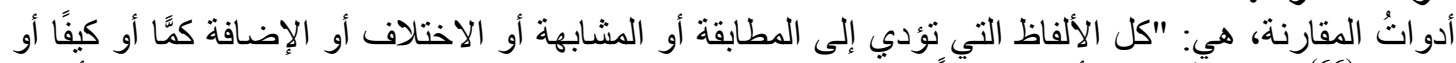

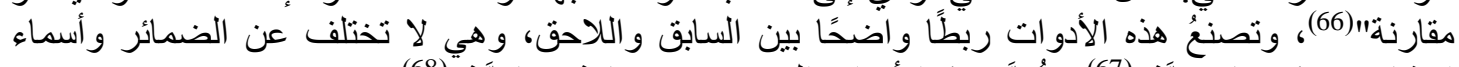

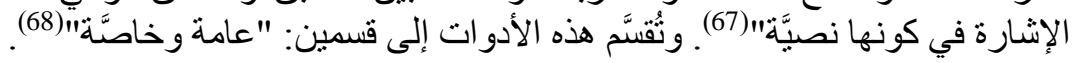

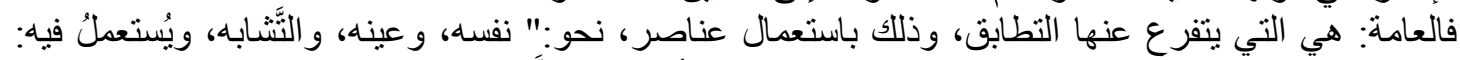

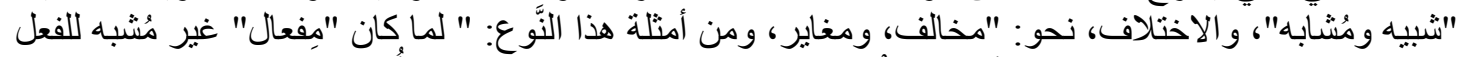

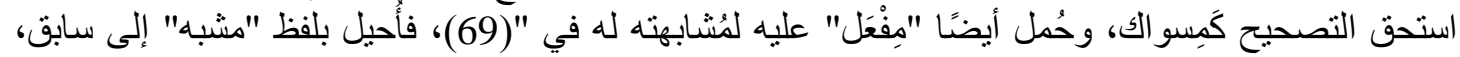

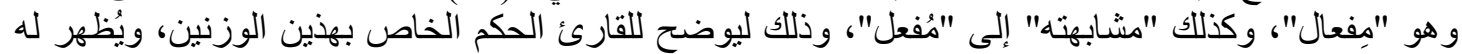

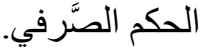

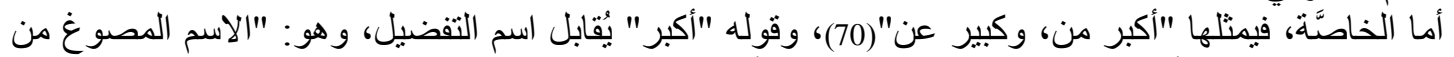

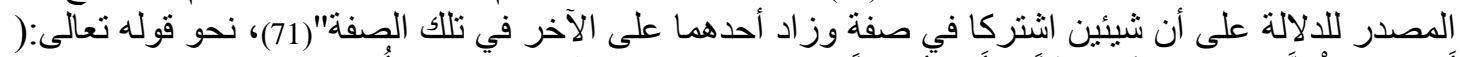

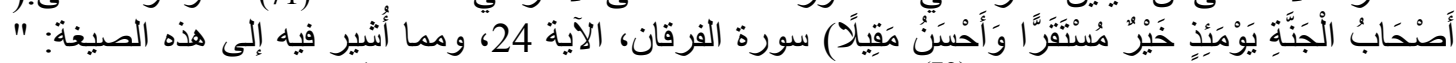

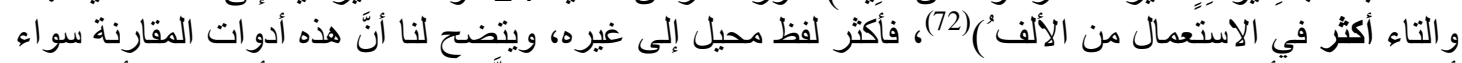

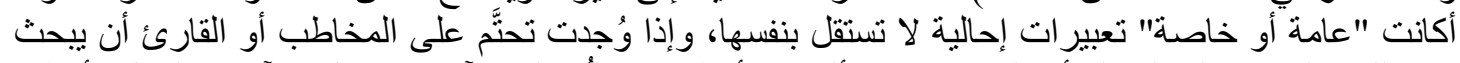

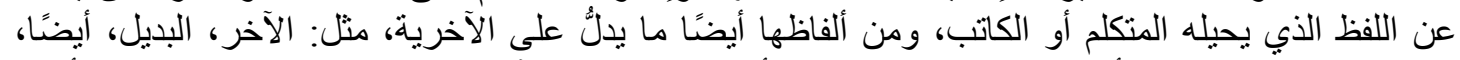

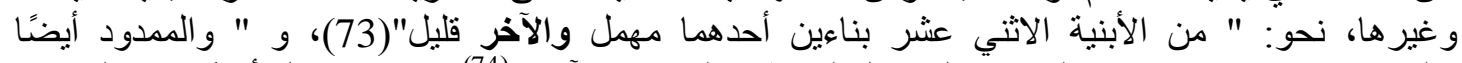

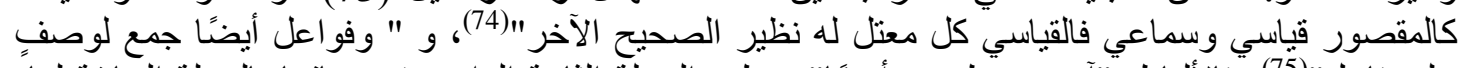

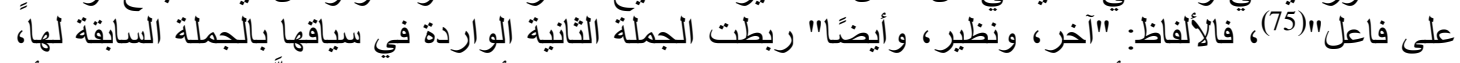

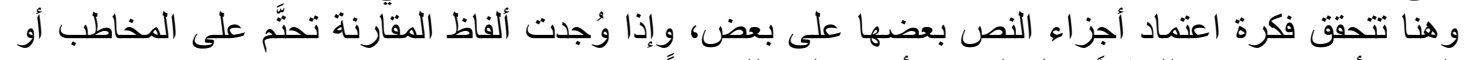

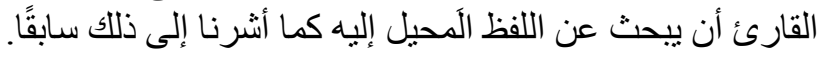

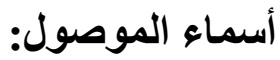

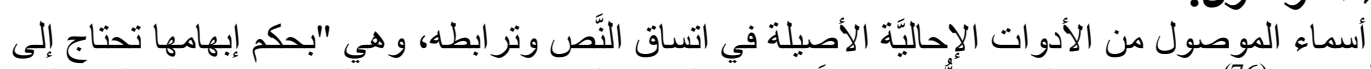

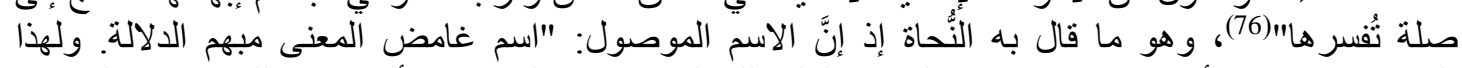

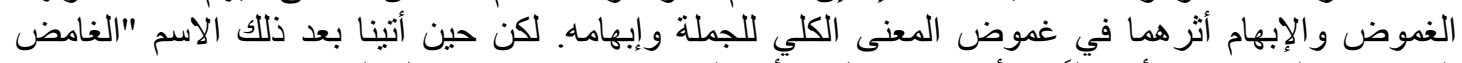

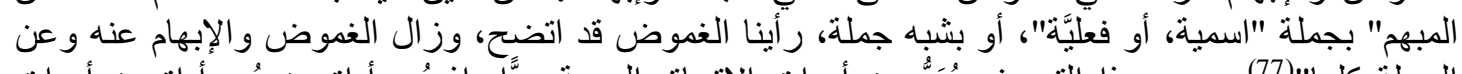

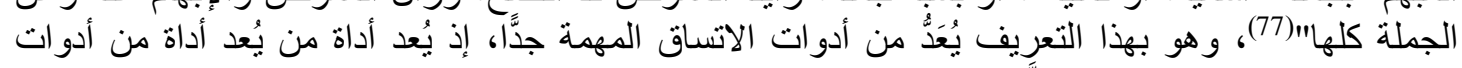

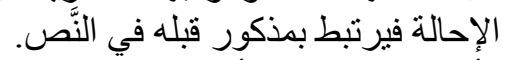

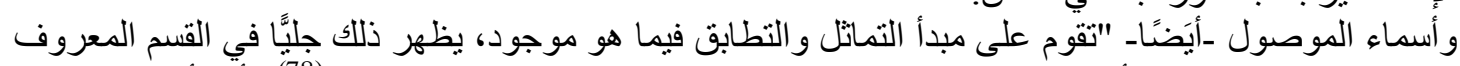

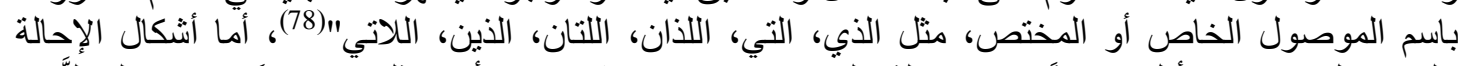

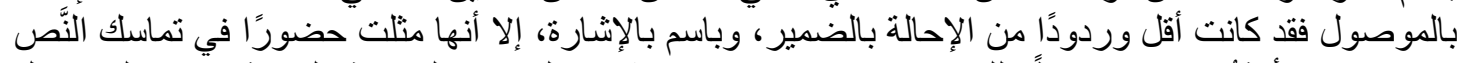

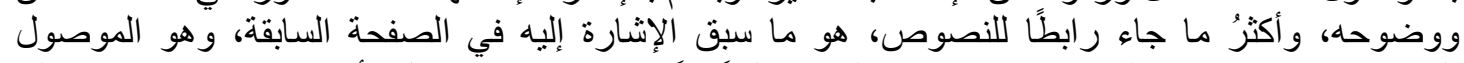

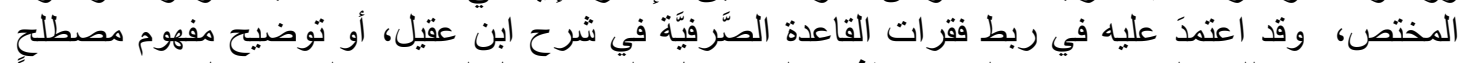

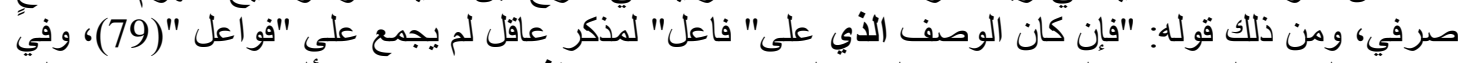

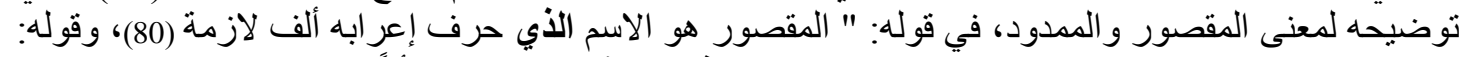

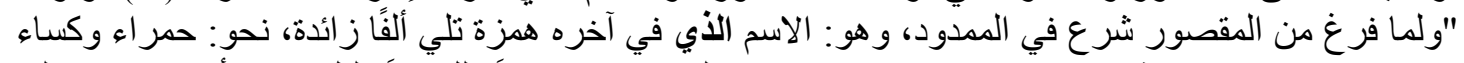

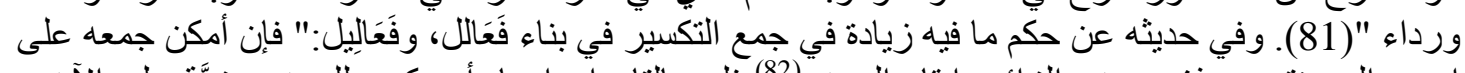

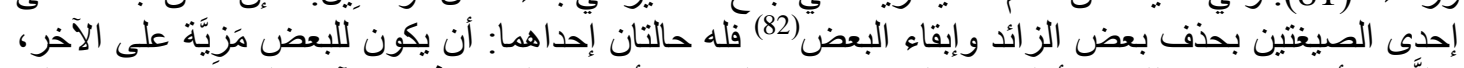

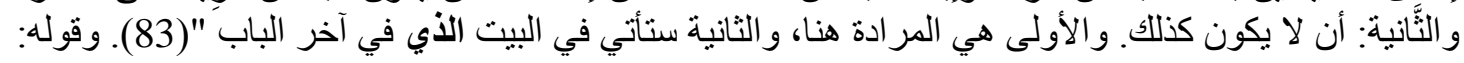




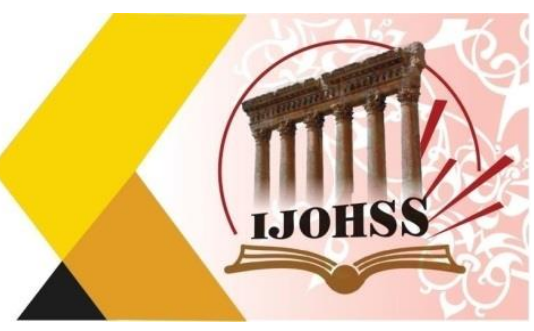

مِن التَّصغير نوعُ يسمى تصغير التَّرخيم، وهو عبارة عن تصغير الاسم بعد تجريده من الزو ائد التي هي فيه

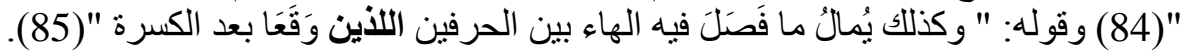

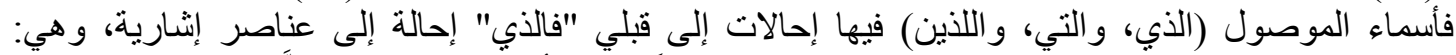

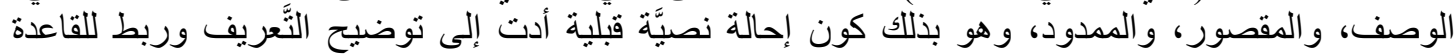

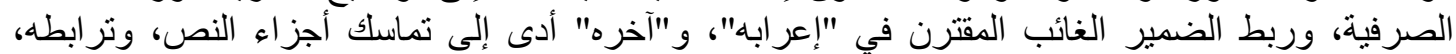

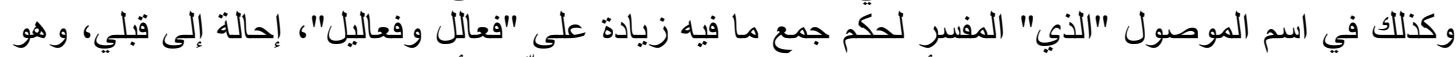

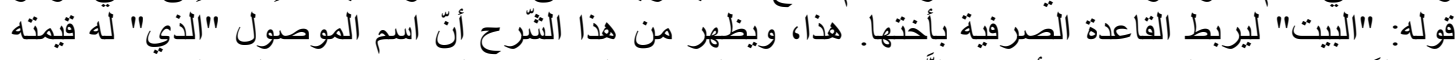

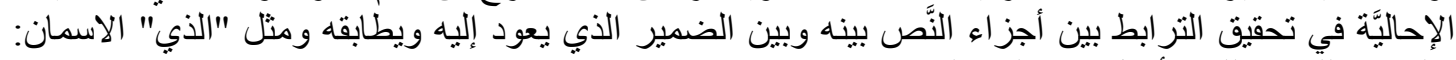
"التي، و اللتين" اللذان أحال بهما إلى قبلي قريب.

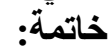

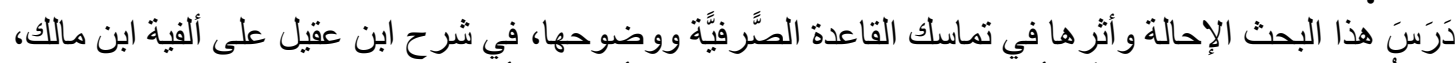

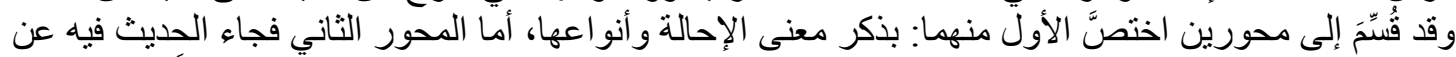

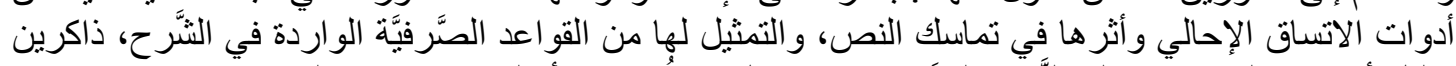

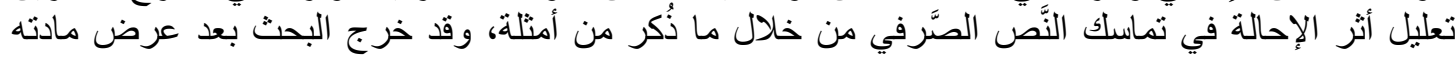

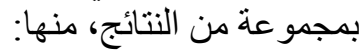

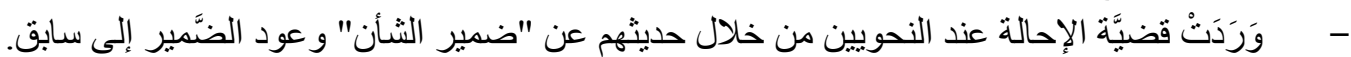

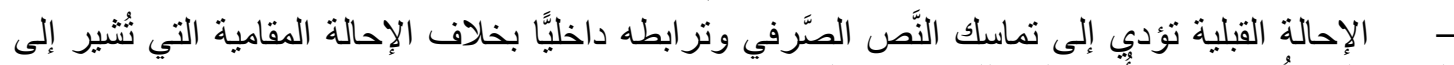

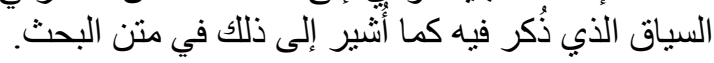

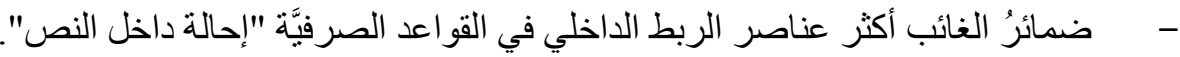

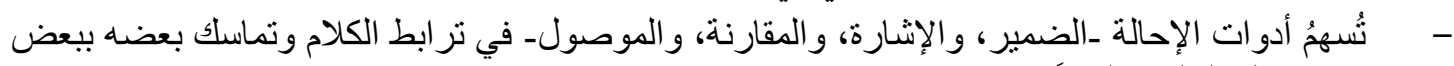
في نو عي الإحالة القبلية و البعديَّة".

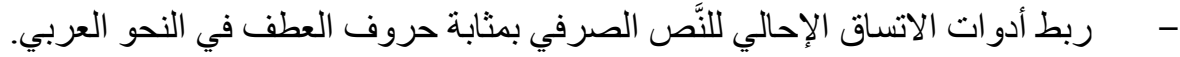

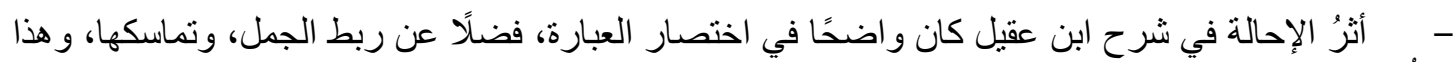

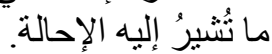

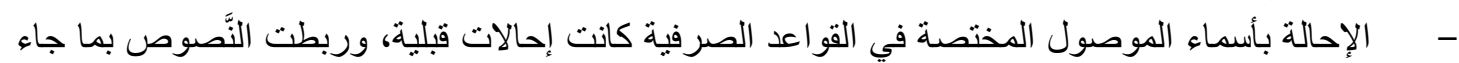

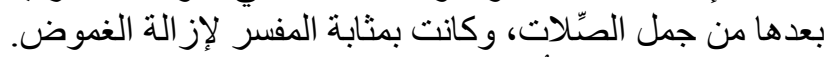

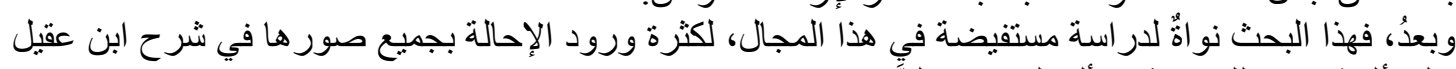

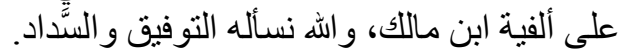
(هذا البحث تم دعمه من خلال البرنامج البحثي العام بعمادة البحث العلمي- جامعة الملك خالدـ المملكة العربية

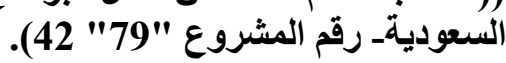

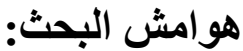

(1) يُنظر على سبيل المثال: القاموس المحيط، الفيروز أبادي، 513/3 ولسان العرب، ابن منظور، 2434/27.

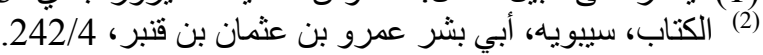

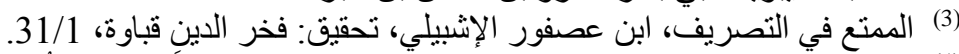

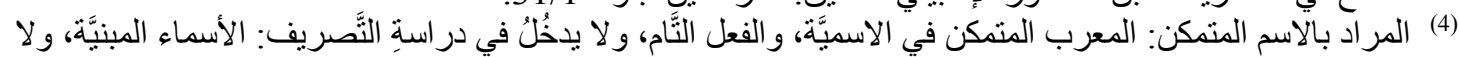

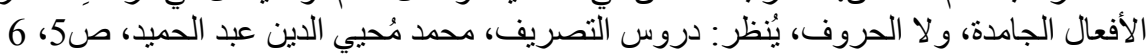

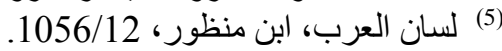

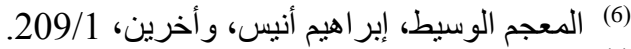

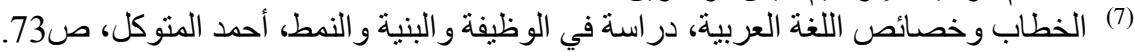

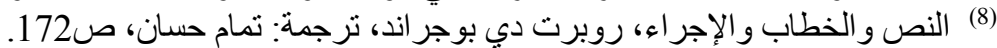




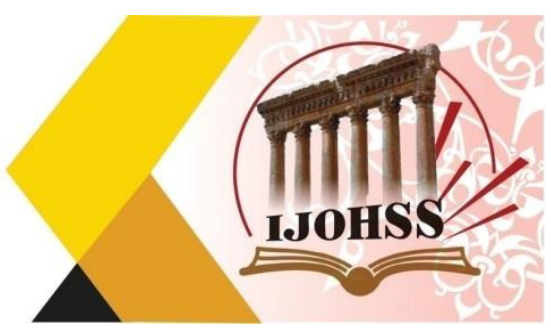

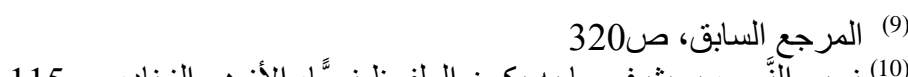

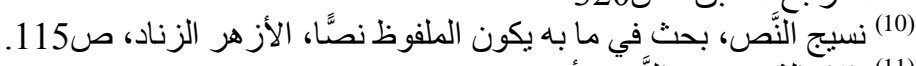

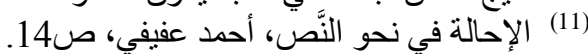

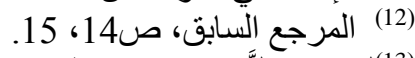

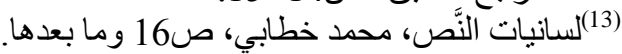
40/1

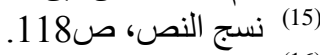

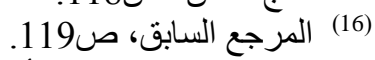
(17) شرح ابن عقيل على ألفية ابن مالك، بهاء الدين عبد الله بن عقيل العقيلي، تحقيق محمد محبي الدين عبد الحميد، $205 / 4$

172/4 (18) المرجع السابق،

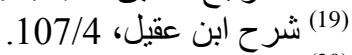
(20) المرجع السابق،

(21) يُنظر شرح ابن الئن عقيل على ألفية ابن مالك، 203/1، والإتقان في علوم القرآن، السيوطي، تحقيق محمد أبو الفضل

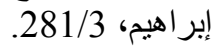
172/4) شرح ابن عقيل،

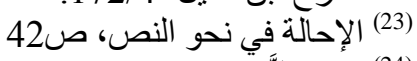

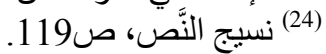
(25) التذييل و التكميل في شر حكتاب التسهيل، أبي حيان محمد بن يوسف، تحقيق: حسن هنداوي، 271/2.

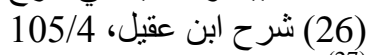

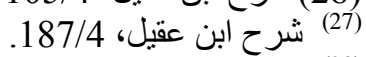

1728) المرجع السابق،

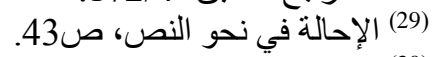

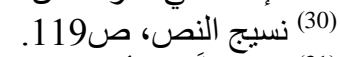

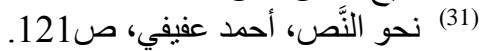
(32) نحو النص ذبي الجملة الو احدة در اسة تطبيقية في في مجمع الأمثال للميداني، محمد قدوم، ص94

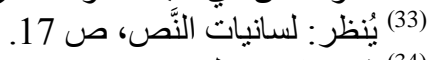

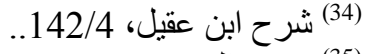

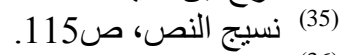

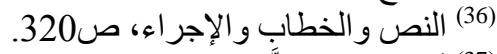

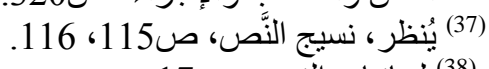

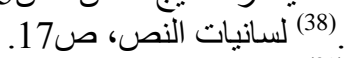

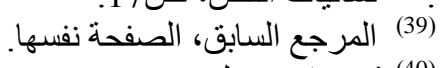
(40) شرح ابن عقيل، 88/1) (41) شرح التسهيل، محمد بن عبد الله بن مالك، تحقيق: عبد الرحمن السيد، ومحمد بدوي المختون، 120/1.

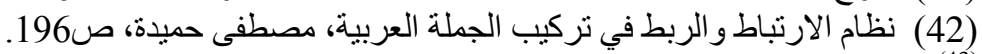

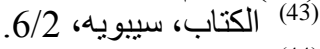

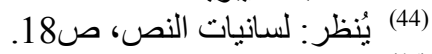
(45) نحو النص ذي الجملة الو احدة، صولنيان

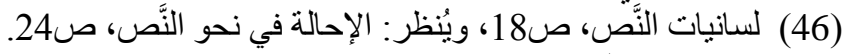

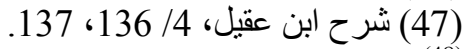

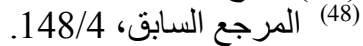

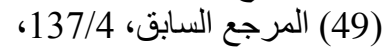

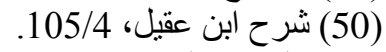
(51) المرجع السابق، 172/4 إنر، 
العدد (21) مايو 2021

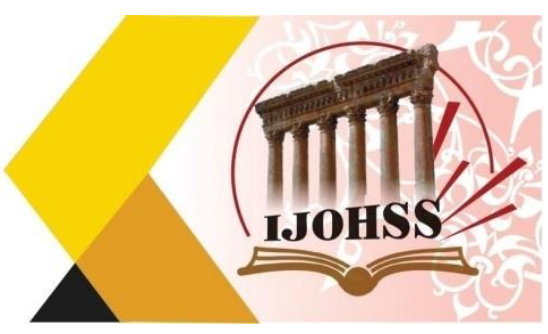

(52) الإحالة في نحو النَّص، ص24.

ئئن

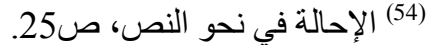

(55) شرح ابن عقيل، 229/4.

(56) (5) المرجع السابق، 239/4.

(57) المرجع السابق، 247/4.

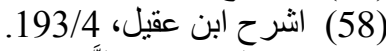

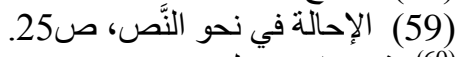

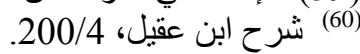

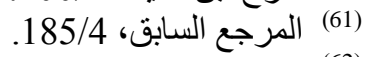

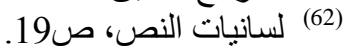

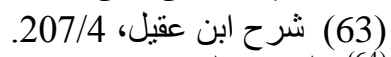

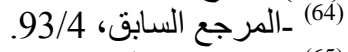

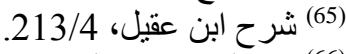

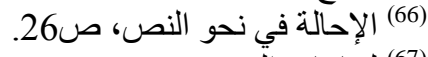

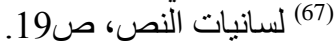

(68) المرجع السابق، الصفة نفسها.

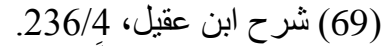

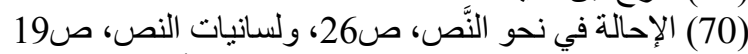

(71) شذا العرف في فن الصرف، الحملاوي، أحمد بن محمد بن أحمد، قدم له و علق عليه: محمد عبد المعطي، ص127.

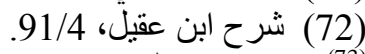

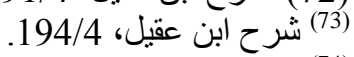

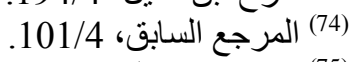

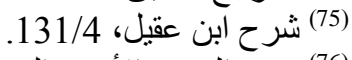

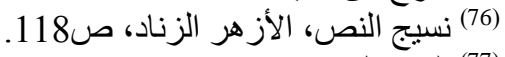

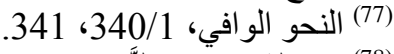

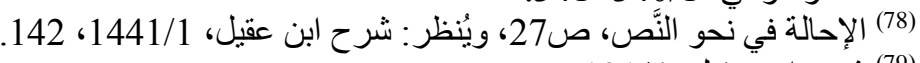

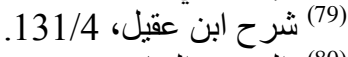

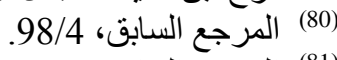

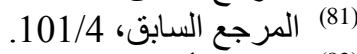

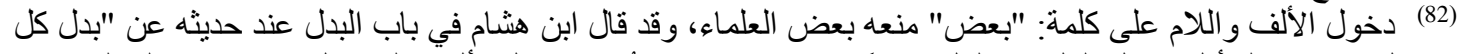

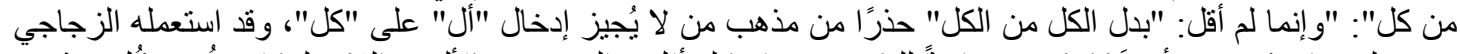

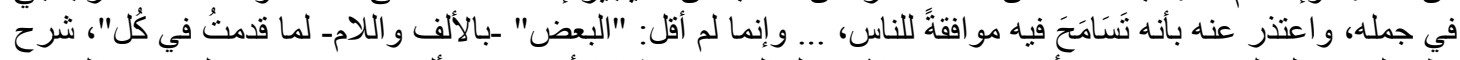

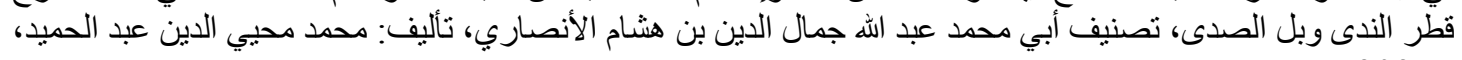
ص صن9.

136/4 (83) شرح ابن عقيل، (84) (149/4)

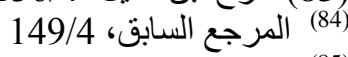

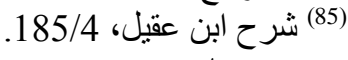

مصادر البحث ومراجعه:

القرآن الكريم.

1. الإتقان في علوم القرآن، السيوطي، آحقيق الحيق محمد أبو الفضل إبراهيم، المكتبة العصرية، بيروت، لبنان، 1988م.

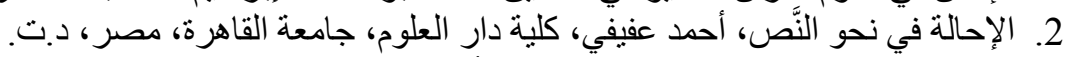

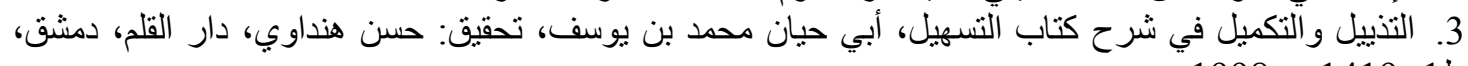

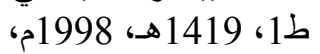




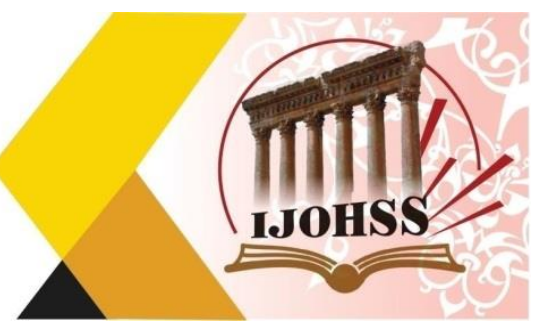

4. الخطاب وخصائص اللغة العربية، دراسة في الوظيفة والبنية والنمط، أحمد المنوكل منشورات الاختلاف،

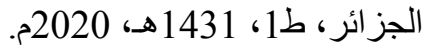

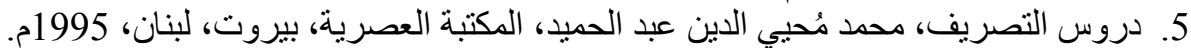
6. شذا العرف في فن الصرف، الحملاوي، أحمد بن محمد بن أحمد، قدم له و وعلق عليه: لئن، محمد عبد المعطي، دار

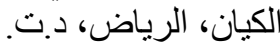
7. شرح ابن عقيل على ألفية ابن مالك، بهاء الدين عبد الله بن عقيل العقيلي، تحقيق محمد محيي الدين عبد الحميد، دار

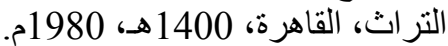
8. شرح التسهيل، محمد بن عبد الله بن مالك، تحقيق: عبد الرحمن السيد، ومحمد بدوي المختون، دار هجر، ط1، 1990م 1410 140

9. شرح قطر الندى وبل الصدى، تصنيف أبي محمد عبد الله جمال الدين بن هشام الأنصاري، تأليف: محمد محيي

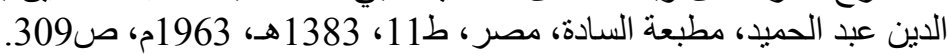

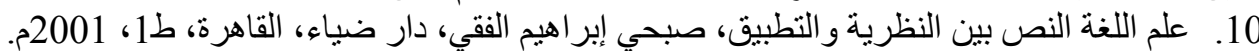

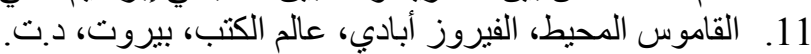

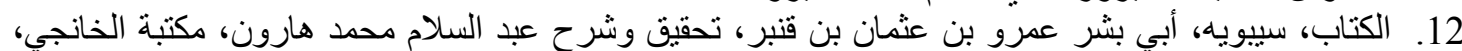
القاهرة، ط3، 1408 1408هـ، 1988م. 1988. 13. لسان العرب، ابن منظور، تحقيق: عبد الله علي الكبير ومحمد أحمد حسب الله وهانثم محمد الثناذلي، دار

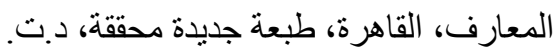

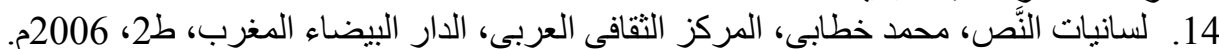

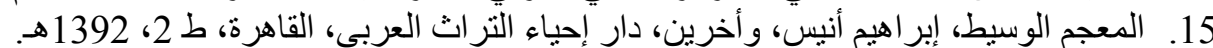
16. الممتع في التصريف، ابن عصفور الإشبيلي، تحقيق: فخر الدين قباوة، دار القياء القلم، حلب، سوريا، 1393ه، 1973م. 1973 17. نحو النص ذي الجملة الواحدة دراسة تطبيقية في مجمع الأمثال للميداني، محمد قدوم، دار وجوه للنشر والتوزيع،

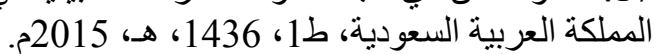

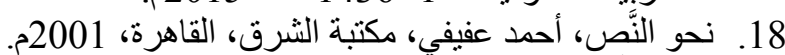

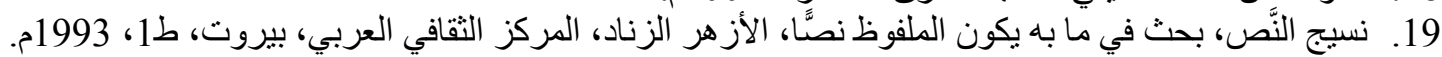
20.

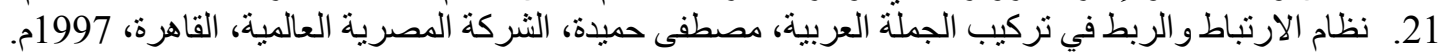

\section{References}

1. Perfection in the Sciences of the Qur'an, Al-Suyuti, verified by Muhammad Abu AlFadl Ibrahim, Al-Asriyya Library, Beirut, Lebanon, 1988 AD.

2. Referral in text grammar, Ahmed Afifi, Faculty of Dar Al Uloom, Cairo University, Egypt, d.

3. Appendix and Complementation in Explaining the Book of Facilitation, Abu Hayyan Muhammad bin Yusuf, edited by: Hasan Hindawi, Dar Al-Qalam, Damascus, 1st Edition, 1419 AH, 1998 AD.

4. Discourse and Characteristics of the Arabic Language, A Study of Function, Structure and Pattern, Ahmad Al-Mutawakel, Al-Ikhtaf Publications, Algeria, 1st Edition, $1431 \mathrm{AH}$, 2020 AD.

5. The Lessons of Conjugation, Muhammad Muhyiddin Abdel Hamid, The Modern Library, Beirut, Lebanon, 1995 AD.

6. The anomaly of the custom in the art of exchange, Al-Hamalawi, Ahmed bin Muhammad bin Ahmed, presented to him and commented on it: Muhammad Abd alMuati, Dar al-Kayan, Riyadh, d 


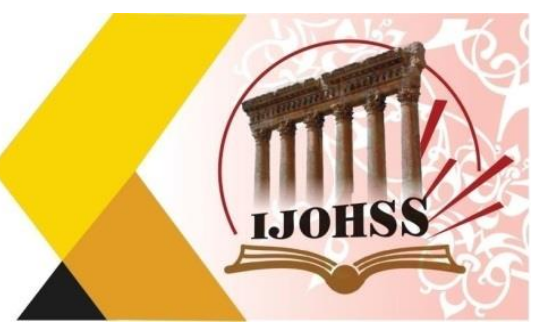

7. Explanation of Ibn Aqil Ali Alfiya Ibn Malik, Bahaa al-Din Abdullah bin Aqeel alAqili, edited by Muhammad Muhi al-Din Abd al-Hamid, Dar al-Turath, Cairo, 1400 AH, $1980 \mathrm{AD}$.

8. Explanation of the facilitation, Muhammad bin Abdullah bin Malik, investigation by: Abd al-Rahman al-Sayyid and Muhammad Badawi al-Mukhtoon, Dar Hajar, 1st Edition, 1410 AH, 1990 AD.

9. Explanation of Qatr al-Nada and Bal al-Echo, the classification of Abu Muhammad Abdullah Jamal al-Din bin Hisham al-Ansari, authored by: Muhammad Muhi al-Din Abd al-Hamid, Al-Sada Press, Egypt, Edition 11, 1383 AH, 1963 AD, p.309.

10. Linguistics, Text between theory and practice, Sobhi Ibrahim Al-Feki, Dar Diaa, Cairo, 1st Edition, 2001 AD.

11. Al-Qamoos Al-Muheet, Al-Fayrouz Abadi, Alam Al-Kutub, Beirut, d.

12. The book, Sibawayh, Abi Bishr Amr bin Othman bin Qanbar, investigation and explanation of Abd al-Salam Muhammad Haroun, Al-Khanji Library, Cairo, 3rd Edition, $1408 \mathrm{AH}, 1988 \mathrm{AD}$.

13- Lisan al-Arab, Ibn Manzoor, edited by: Abdullah Ali al-Kabir, Muhammad Ahmad Hassaballah and Hashem Muhammad al-Shazly, Dar al-Maarif, Cairo, a new edited edition, $d$.

14. Linguistics of the text, Muhammad Khatabi, Arab Cultural Center, Casablanca, Morocco, 2nd Edition, 2006 AD.

15. Al-Waseet Lexicon, Ibrahim Anis, and others, House of Revival of Arab Heritage, Cairo, 2nd Edition, $1392 \mathrm{AH}$.

16. Al-Mumti 'fi al-Tasrif, Ibn Asfour al-Ishbili, edited by: Fakhr al-Din Qabawa, Dar alQalam, Aleppo, Syria, 1393 AH, 1973 CE.

17. Towards a one-sentence text, an applied study in the Al-Amthal Complex for AlMidani, Muhammad Qaddum, House of Faces for Publishing and Distribution, Kingdom of Saudi Arabia, Edition 1, 1436 AH, 2015 AD.

18. Towards the Text, Ahmed Afifi, Al Sharq Library, Cairo, 2001 AD.

19. Naseej Al-Nass, a study of what the spoken word is a text, Al-Azhar Al-Zinad, Arab Cultural Center, Beirut, 1st Edition, 1993 AD.

20. Text, discourse and procedure, Robert de Bougrand, translation: Tamam Hassan, The World of Books, Cairo, 1418 AH, 1998 AD.

21. Linking and Connecting System in the Synthesis of the Arabic Sentence, Mustafa Hamida, Egyptian International Company, Cairo, 1997. 